\title{
Understanding the HIV/STI risks and prevention needs of men who have sex with men in Nairobi, Kenya
}

Washington Onyango-Ouma

Harriet Birungi

Population Council

Scott Geibel

Population Council

Follow this and additional works at: https://knowledgecommons.popcouncil.org/departments_sbsr-hiv

Part of the Demography, Population, and Ecology Commons, Gender and Sexuality Commons, Health Policy Commons, Immune System Diseases Commons, International Public Health Commons, Medicine and Health Commons, Public Health Education and Promotion Commons, and the Virus Diseases Commons How does access to this work benefit you? Let us know!

\section{Recommended Citation}

Onyango-Ouma, Washington, Harriet Birungi, and Scott Geibel. 2005. "Understanding the HIV/STI risks and prevention needs of men who have sex with men in Nairobi, Kenya," Horizons Final Report. Washington, DC: Population Council. 


\section{Understanding the HIV/STI Risks and Prevention Needs of Men Who Have Sex With Men in Nairobi, Kenya}

\section{Hprizons




\title{
Understanding the HIV/ STI Risks and Prevention Needs of Men Who Have Sex With Men in Nairobi, Kenya
}

\author{
W. Onyango-Ouma ${ }^{1}$, Harriet Birungi ${ }^{2}$, \\ and Scott Geibel ${ }^{3}$
}

\section{FRONTIERS \\ IN REPRODUCTIVE HEALTH}

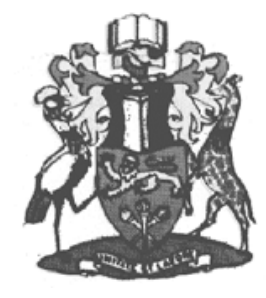

\section{Hgrizons}

${ }^{1}$ Institute of African Studies/University of Nairobi ${ }^{2}$ FRONTIERS/Population Council

${ }^{3}$ Horizons/Population Council 


\section{Acknowledgments}

The researchers would like to acknowledge Sam Kalibala and Chris Castle for their contributions as study co-investigators during the conceptualization, planning, and initial implementation stages. The team would also like to acknowledge Professor Isaac Nyamongo, of the Institute of African Studies (IAS) at the University of Nairobi, who provided support and substantive contributions throughout the project. In addition, the technical advice and support of individuals from the following organizations are greatly appreciated: USAID/Kenya, Kenya National AIDS Control Program (NASCOP), Kenya National Council for Science and Technology (NCST), and Liverpool VCT Centre.

During the fieldwork phase, Emmanuel Kamau, Jeremy Mirie, and the interviewing team of Alex Rutto, Moses Orege, and Eric Murage provided valuable assistance and advice that made the survey possible.

We are grateful to Dr. Julius Rogena, who kindly provided technical and medical advice during the course of the study; the legal advice from advocate Otiende Amollo was also highly appreciated. We are indebted to the staff of the International Centre for Reproductive Health (ICRH) in Mombasa for their assistance during the pre-test of the data collection tools. Placide Tapsoba (Population Council, Accra) and Amadou Moreau (Population Council, Dakar) provided valuable advice and assistance throughout the study. We also thank Susan Kaai and Norah Omenda (Population Council, Nairobi) for their respective technical and administrative support. Chris Castle of the United Nations Educational, Scientific and Cultural Organization (UNESCO), Eliya Zulu and Chi-Chi Undie of the African Population and Health Research Center (APHRC), Edward Kunyanga of Macro International, Inc., and Naomi Rutenberg, Ellen Weiss, and Julie Pulerwitz of the Population Council, Washington, D.C., reviewed the report.

Above all, we would like to thank the individuals who agreed to participate in this research.

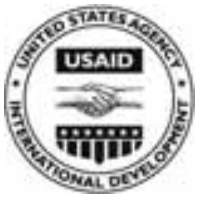

This research was supported by the Horizons Program, which is implemented by the Population Council in collaboration with the International Center for Research on Women, International HIV/AIDS Alliance, PATH, Tulane University, Family Health International, and Johns Hopkins University. Horizons is funded by the President's Emergency Plan for AIDS Relief through the U.S. Agency for International Development, under the terms of HRNA-00-97-00012-00. The opinions expressed herein are those of the authors and do not necessarily reflect the views of the U.S. Agency for International Development.

Published in September 2005.

\section{Population Council}

The Population Council is an international, nonprofit, nongovernmental institution that seeks to improve the well-being and reproductive health of current and future generations around the world and to help achieve a humane, equitable and sustainable balance between people and resources. The Council conducts biomedical, social science, and public health research and helps build research capacities in developing countries. Established in 1952, the Council is governed by an international board of trustees. Its New York headquarters supports a global network of regional and country offices.

Copyright (C) 2005 The Population Council Inc.

This document may be reproduced in whole or in part without permission of the Population Council provided full source citation is given and the reproduction is not for commercial purposes.

Suggested citation: Onyango-Ouma, W., Harriet Birungi, and Scott Geibel. 2005. "Understanding the HIV/STI risks and prevention needs of men who have sex with men in Nairobi, Kenya," Horizons Final Report. Washington, D.C.: Population Council. 


\section{Table of Contents}

\section{Abbreviations and Acronyms}

Executive Summary 1

I ntroduction $\quad 7$

Background $\quad 7$

Objectives $\quad 8$

$\begin{array}{lr}\text { Ethical considerations } & 8\end{array}$

Methodology 11

Study design $\quad 11$

Study limitations $\quad 14$

$\begin{array}{ll}\text { Results } & 15\end{array}$

$\begin{array}{ll}\text { Profile of respondents } & 15\end{array}$

$\begin{array}{ll}\text { Sexual identities } & 17\end{array}$

$\begin{array}{ll}\text { Social networks } & 20\end{array}$

Stigma, discrimination, and violence $\quad 22$

Knowledge of HIV and STIs $\quad 24$

$\begin{array}{ll}\text { Sexual practices } & 26\end{array}$

Condom and lubrication use $\quad 29$

Factors associated with unprotected sex $\quad 31$

Reported STI symptoms and treatment 34

Factors associated with STI symptoms 36

HIV testing $\quad 39$

Access to health care and provider preferences 41

Conclusion and Recommendations 44

References 46 


\section{Abbreviations and Acronyms}

$\begin{array}{ll}\text { AIDS } & \begin{array}{l}\text { acquired immune deficiency syndrome } \\ \text { community-based organization } \\ \text { cBO }\end{array} \\ \text { CI } & \text { Demfidence interval } \\ \text { DHS } & \text { Government of Kenya } \\ \text { GOK } & \text { Institute of African Studies } \\ \text { HIV } & \text { Institutional Review Board } \\ \text { IAS } & \text { Kenya Shillings } \\ \text { IRB } & \text { men who have sex with men } \\ \text { KSH } & \text { non-governmental organization } \\ \text { MSM } & \text { odds ratio } \\ \text { NGO } & \text { sexually transmitted infection } \\ \text { OR } & \text { unprotected anal insertive intercourse } \\ \text { STI } & \text { unprotected anal receptive intercourse } \\ \text { UAI } & \text { United States Agency for International Development } \\ \text { UAR } & \text { voluntary counseling and testing } \\ \text { USAID } & \end{array}$




\section{Executive Summary}

Understanding the sexual behaviors of populations who are vulnerable to HIV is an important component in the battle against the AIDS pandemic. Yet policymakers in developing countries, particularly in Africa, have often overlooked men who have sex with men (MSM) as a vulnerable group because of stigmatization of homosexual behavior and denial of the existence of MSM and the role they may play in HIV transmission (McKenna 1996; Parker et al. 1990). A growing body of literature, however, not only documents the presence of this population in Africa (Murray and Roscoe 1998; Simooya 2001; Niang et al. 2003; Attipoe 2004) but also the importance of reaching them with information and services to prevent HIV and other sexually transmitted infections (STIs) (UNAIDS 2000; Office of the United States Global AIDS Coordinator 2004).

Despite increasing awareness of the role MSM can play in the dynamics of HIV transmission in Africa, research on MSM in Kenya has been limited. In response to this gap, researchers from the Institute of African Studies (IAS) at the University of Nairobi and the Horizons and FRONTIERS Programs of the Population Council undertook a study of MSM in Nairobi from 2003 to 2004. The overall goals of the study were to understand the extent to which MSM are at risk of HIV and other STIs, identify the factors associated with risk behaviors, and identify MSM sexual health needs in order to develop appropriate interventions. The study proposal received full ethical review and clearance from the Population Council Institutional Review Board (IRB) in New York, the Kenya National Council for Science and Technology, and the Kenyatta National Hospital Ethics and Research Committee in Nairobi. Approval from all review boards was achieved by November 2003, and research activities were conducted between February and August 2004.

Systematic data collection methods included (a) a quantitative survey of $500 \mathrm{MSM}$; (b) in-depth interviews with MSM, gatekeepers, ${ }^{1}$ and service providers; and (c) ethnographic observations in MSM social settings. The quantitative survey was implemented first, in early 2004, followed by the in-depth interviews and ethnographic observations; all respondents gave informed consent to participate in the study.

\section{Key Findings}

\section{MSM are not a negligible population in Nairobi.}

Within two months, 500 Kenyan MSM informants were identified through snowball sampling and interviewed for the study. Respondents were from diverse socioeconomic backgrounds, ranging from the unemployed to educated professionals. The survey sample included those with no occupation (15 percent), students (21 percent), sex workers (14 percent), small-scale earners (16 percent), professional or steady income earners (15 percent), and those with jobs in which they

\footnotetext{
${ }^{1}$ Gatekeepers are defined for this report as individuals who are in jobs/employment that put them in routine social and/or professional contact with MSM during the course of their duties. Occupations of typical gatekeepers included masseurs, hairdressers, musicians, taxi drivers, tour operators, and hotel/restaurant staff. A gatekeeper may or may not be an MSM.
} 


\section{Hgrizons}

regularly interacted with MSM, as determined by the study's ethnographic observations, such as masseurs, hairdressers, musicians, and taxi drivers (19 percent).

\section{The sexual behavior of MSM has implications for both men's and women's reproductive health.}

Over two-thirds of MSM (69 percent) reported ever having sex with a woman; seven percent of respondents are currently married and seven percent have been divorced/separated/widowed. Twenty-two percent reported having at least one child. Many MSM remain sexually active with women, as 20 percent (of those who have ever had sex with a woman; $n=344$ ) reported having vaginal sex in the past month, and 7 percent reported having anal sex with a woman in the past month. When reporting sexual identities, 23 percent of MSM stated they were bisexual.

\section{MSM are vulnerable to stigma, discrimination, and violence.}

Most MSM perceive community stigma and discrimination to be a major problem in their lives. When asked about topics discussed with friends, stigma-related issues were the topics most-often discussed (63 percent). Stigmatizing/discriminatory incidents in the past 12 months, such as public humiliation, were reported by 33 percent of respondents, while incidents of verbal, physical, and sexual violence were reported by 22 percent. Survey findings show that sex workers were significantly more likely than other MSM to report an incident of stigma/discrimination (59 percent to 29 percent; $p<0.001$ ) and violence (39 percent to 19 percent; $p<0.001$ ) in the previous year.

\section{Sex with multiple partners is high.}

Within the past month, 47 percent of respondents reported having two or more partners, while 79 percent reported having two or more partners within the past year. The median number of partners in the past year was three, which does not reflect 30 percent of the sample that "could not remember the actual number" of partners. In addition there is a substantial subgroup (21 percent) that reported having only one partner in the previous year.

\section{Reported condom use is high.}

Condoms are widely available throughout Nairobi, and 77 percent of MSM are aware that consistent condom use helps prevent STI/HIV transmission. 75 percent reported using a condom at last anal sex with a male partner; and 58 percent reported "always" using condoms. During the survey, respondents were asked if they were carrying condoms and 13 percent were able to show one to the interviewer. "Never use" of condoms was reported by 11 percent, and was significantly associated with having only one male partner in the past year $(\mathrm{p}<0.001)$. 


\section{Use of oil-based lubricants, which can make condoms vulnerable to breakage, was common.}

While lubrication for anal sex was reportedly used by 92 percent of respondents, the most commonly used lubricant was Vaseline/petroleum jelly (used by 84 percent). Water-based lubricants such as KY Jelly were used by 41 percent of respondents, but only 26 percent of MSM who know about lubrication $(n=475)$ correctly knew that only a water-based lubricant should be used with latex condoms.

\section{Key factors associated with unprotected sex with men were having only one partner in the past 12 months, and having been the victim of violence in the past 12 months.}

Multivariate analysis revealed that having one partner in the past 12 months was an important predictor of unprotected sex at last receptive anal sex (OR $=2.44,95 \% \mathrm{CI}: 1.32-4.52$,

$\mathrm{p}<0.01)$, unprotected sex at last insertive anal sex (OR $=2.57,95 \% \mathrm{CI}: 1.48-4.46, \mathrm{p}<0.05)$, and never use of condoms (OR $=3.23,95 \% \mathrm{CI}: 1.68-6.19, \mathrm{p}<0.001)$. More than half (51 percent) of those who did not use a condom at last sex $(n=124)$ did so because they trusted their partner.

Victims of physical, verbal, or other forms of violence in the past 12 months, however, were also significantly more likely to not use a condom at last receptive anal sex $(\mathrm{OR}=2.44,95 \%$ CI: 1.35 $4.39, \mathrm{p}<0.01)$, have unprotected sex at last insertive anal sex $(\mathrm{OR}=1.96,95 \% \mathrm{CI}: 1.13-3.37, \mathrm{p}<$ $0.05)$, and to "never use" condoms $(\mathrm{OR}=2.45,95 \%$ CI: $1.24-4.84, \mathrm{p}<0.05)$. This may reflect that MSM whose lives are characterized by violence are less able to negotiate condom use than other MSM.

\section{Prevalence of reported STI symptoms is higher than among men in the Nairobi general population.}

Genital/anal discharge in the past 12 months was reported by six percent of respondents, and genital/anal sores were reported by five percent. This is higher than a general population sample of Nairobi men from the 2003 Demographic and Health Survey (DHS), where only one percent reported having abnormal genital discharge and two percent reported having genital sores/ulcers in the past 12 months. Other symptoms reported by MSM in the past 12 months were genital pain (12 percent), burning urination (14 percent), and genital/anal itching (11 percent). Forty-seven percent reported ever having an STI symptom, of which 80 percent $(\mathrm{n}=233)$ sought treatment during the last episode.

\section{The practice of oral sex is associated with reported STI symptoms.}

Multivariate analysis revealed that MSM who practice oral sex were significantly more likely than other MSM to report at least one STI symptom in the past 12 months $(\mathrm{OR}=2.30,95 \% \mathrm{CI}: 1.40$ $3.77, \mathrm{p}<0.01)$. Further analysis showed that genital/anal discharge and genital/anal sores were reported almost exclusively by MSM who practice oral sex (genital/anal discharge, 9 percent to 1 


\section{Hgrizons}

percent, $\mathrm{p}<0.001$; genital/anal sores, 8 percent to 0 percent, $\mathrm{p}<0.001$ ). The practice of oral sex may be a complex indicator of risky sexual behavior, as well as a potential route of transmission for some STIs.

\section{A majority of MSM in the study has had an HIV test.}

More than half of respondents (57 percent) reported ever taking an HIV test. This is more than twice the rate of general population males in Nairobi Province (27 percent), according to the 2003 DHS. Of MSM who took an HIV test $(n=286), 98$ percent received their test results, and 70 percent had the test performed within the past 12 months.

\section{Confidentiality is the most important factor for MSM when choosing a treatment facility.}

MSM desire and seek professional medical care and treatment, and they seek treatment in medical facilities such as clinics, hospitals, and health centers, which are widely available throughout Nairobi. MSM still have difficulty, however, finding providers trained to meet and advise their unique and specific sexual health needs. MSM prefer to receive STI treatment and/or HIV counseling in private clinics because they are perceived to provide greater confidentiality. Other criteria cited by MSM in treatment-seeking included affordability and close access to quality care.

\section{Many health providers are largely aware that MSM exist and are seeking treatment at their facilities, but prefer not to discuss treatment and counseling issues with them.}

In-depth interviews with providers at facilities frequented by MSM survey respondents indicated that these providers see patients with anal sores or ulcers in the throat. According to MSM respondents and providers, MSM do not approach providers for specific advice, as they fear exposure to the legal system, or that providers will discriminate against them. Also widespread stigmatization of sex between men prevents providers from discussing special prevention issues with MSM, or among clinic staff.

\section{Conclusions and Recommendations}

The results from this research provide important information on the background characteristics, sexual behavior, and health-seeking practices of a sample of MSM in Nairobi, Kenya. Despite the limitations of the snowball sampling methodology, researchers were able to reach a diverse group of MSM and elicit qualitative and quantitative data that can be used to inform HIV/STI programming in Kenya. The study also shows that research on MSM can be done in Kenya despite such obstacles as widespread stigmatization of MSM behavior and the fact that it is illegal.

Overall, the survey data indicate that a majority of MSM respondents are aware of HIV/STI risks and are taking steps to protect their health. These steps include getting tested for HIV, seeking 
professional treatment for STI symptoms, and using condoms. However, condom use is not universal, particularly among those who are in long-term sexual relationships with only one partner, and/or are victims of physical, verbal, and/or sexual violence. Moreover, the prevalence of reported STI symptoms is higher in the study sample than in men in the general population (DHS 2003), which may facilitate the acquisition and transmission of HIV.

The ease with which this study recruited 500 men through snowball sampling suggests that the population of Kenyan MSM living in Nairobi is larger than is commonly believed. This situation, combined with the existence of risk behaviors, such as unprotected sex, among the study sample may have implications for the development of localized STI and HIV epidemics. Therefore, interventions targeted to this population are urgently needed. These interventions could include the following:

\section{Specialized counseling as part of voluntary counseling and testing (VCT) and STI services that is confidential and sensitive to the HIV/STI prevention needs of MSM.}

Although a high percentage of MSM in the survey sample have taken an HIV test, VCT services have not trained counselors to provide care and advice to meet the specific sexual health needs of MSM. The situation is similar in many STI clinics, where providers rarely discuss treatment and prevention issues relevant to their MSM clients. Stigmatizing attitudes of providers and their lack of sensitivity are significant barriers to receiving appropriate health services. MSM desire confidential, affordable, and quality care, and prefer to receive this care from professional health care providers. To improve utilization, services will need to respond to MSM concerns about stigmatization of their sexual behavior and their desire for strict confidentiality. Thus, VCT and STI clinic staff need training on the HIV/STI prevention needs of MSM, counseling strategies for addressing risk behaviors, and the importance of confidential and de-stigmatizing service delivery.

\section{Peer education that addresses the HIV/STI risks of multiple partners, unprotected sex, and incorrect use of lubrication.}

The study found that other MSM - whether as partners or friends - play an important role in passing on information about HIV and other STIs. These discussions revolve around preventive and protective measures that can be adopted by MSM and that respond to their needs. Study findings also highlight the importance of increasing exposure to discussions about HIV/STIs between MSM because respondents who had attended a discussion group or session were significantly more likely to use condoms. In addition, a high proportion of survey respondents noted that they would seek advice regarding STI symptoms from other MSM, which also supports the notion of training MSM as HIV/STI peer educators.

These peer educators could be trained to encourage the use of water-based lubricants for anal sex, the use of condoms for any penetrative sex act with male or female partners, and a reduction in the number of sexual partners. Peer educators could also help MSM explore the issues of partner trust and intimacy as barriers to condom use, particularly among those in longer-term relationships with 


\section{Hgrizons}

a single partner. These issues are not unique to MSM, but are also formidable obstacles to condom use within heterosexual relationships.

Peer education may also have an important role to play in helping MSM who are more marginalized within society - those who have been victims of stigma, discrimination, or violence. The study found that these MSM were more likely to engage in unprotected sex and report STI symptoms. A peer education program that emphasizes personal empowerment and responsibility, and offers social support may help this particularly vulnerable population to adopt HIV/STI protective behaviors. 


\section{I ntroduction}

\section{Background}

Understanding the sexual behaviors of populations who are vulnerable to HIV is an important component in the battle against the AIDS pandemic. Yet policymakers in developing countries, particularly in Africa, have often overlooked men who have sex with men (MSM) as a vulnerable group because of widespread stigmatization of homosexual behavior and denial of their existence and the role they may play in HIV transmission (McKenna 1996; Parker, Herdt, and Carballo 1991). However, a growing body of research highlights the existence of this population in Africa (Murray and Roscoe 1998; Simooya 2001; Niang et al. 2003; Attipoe 2004) as well as the importance of reaching them with information and services to prevent HIV and other sexually transmitted infections (STIs) (UNAIDS 2000).

"Some of the populations most affected by HIV/AIDS are the most difficult to reach through conventional health programs... men who have sex with men...are among those who are most marginalized in society and have the least access to basic health care. Developing and implementing interventions with some of these groups is even more difficult because of stigma and discrimination."

-Office of the United States Global AIDS Coordinator (2004)

In a study of 250 MSM in Dakar, Senegal, Niang et al. (2003) found that many men were at high risk of contracting HIV because of unprotected anal intercourse, a history of STI symptoms, and poor knowledge of STIs. Because anal intercourse is a more efficient way of transmitting HIV than vaginal intercourse (UNAIDS website) and because STIs can facilitate the transmission of HIV (Hanson et al. 2005), the researchers concluded that the study population was in great need of STI/HIV interventions. They also noted that interventions for MSM need to be confidential and nonstigmatizing because the lives of many of the men in their sample were characterized by stigma, violence, and rejection as a result of their sexual relationships.

Despite increasing awareness of the role MSM may play in the dynamics of HIV transmission in Africa, research on MSM in Kenya has been limited. Although a study on male genital hygiene and sexual risk behaviors found a subgroup of men who reported male-to-male sex (Sharma et al. 2004), behavioral research on MSM to inform HIV prevention interventions in Kenya has been lacking.

In response to this gap, researchers from the Institute of African Studies (IAS) at the University of Nairobi and the Horizons and FRONTIERS Programs of the Population Council undertook a study of MSM in Nairobi from 2003 to 2004. The researchers began the study by establishing contact with representatives of three Nairobi-area MSM organizations. The first organization, Galebitra, states that its role is to protect and fight for the rights of gay, lesbian, bisexual, and transgender members of Kenyan society. The second organization, Ishtar, was established in 1997 with a mission to educate its members and others about HIV/AIDS. A third organization, Tommick, aims to influence policy and advocate for gay rights. Although Ishtar claims 300-500 members and 


\section{Hgrizons}

Galebitra over 50 members, the membership of these organizations tends to be very fluid, and these figures may be overestimates.

At an initial meeting held on November 23, 2001, members of Ishtar told IAS and Horizons researchers that poverty greatly influenced their sexual behavior-more than two thirds of the 27 members attending the meeting said they had been involved in transactional sex-and that condom use was rare among their members. At this and other meetings MSM contacts also told researchers that seeking health care for STI symptoms was difficult because certain STI symptoms might reveal their sexual orientation to health providers. MSM desired more input into developing policies and programs that would establish MSM-related health services.

As a result of these formative meetings and interviews, IAS and Horizons developed a proposal for research to understand the sexual health needs of MSM in Nairobi in order to identify HIV/STI prevention interventions for this population. Although some MSM contacts were involved from the beginning and provided input into the proposal, it took time for the researchers to develop a relationship of trust with other MSM in Nairobi, which was crucial for the successful conduct of the study. The research team perceived that stigmatization and criminalization of MSM sexual behavior could act as barriers to participation, therefore they invested a lot of time in gaining the trust of formal and informal groups of MSM and assuring them that safeguards were in place to guarantee the confidentiality of informants.

\section{Objectives}

The overall goals of the study were to understand the extent to which MSM are at risk of HIV and other STIs, identify the factors associated with risk behaviors, and determine the sexual health needs of MSM in order to develop appropriate interventions. To achieve these goals, the study objectives were to:

- Examine safe and unsafe sexual practices of MSM, focusing on:

o Sexual identities, sexual and social networks, and partner relations

o Condom and lubricant use

- Describe stigmatizing and discriminatory responses to MSM at the individual, program, and health system levels.

- Examine health-seeking behavior and identify obstacles to obtaining treatment and counseling for STIs and HIV.

- Propose strategies to meet the HIV/STI prevention needs of MSM.

\section{Ethical Considerations}

\section{Ethical review and the study advisory committee}

As the protection of the study informants was of great concern, the research team made a strategic decision to present the study proposal for review to three ethical review boards - one in the United States and two in Kenya. These committees were the Population Council IRB in New York, the 
National Council for Science and Technology, and the Kenyatta National Hospital Ethics and Research Committee in Nairobi. Approval from all review boards was obtained by November 2003 (Table 1).

Table 1 Timeline of study activities

\begin{tabular}{ll}
\hline July 2003 & $\begin{array}{l}\text { Proposal approved by USAID. First study } \\
\text { advisory committee meeting }\end{array}$ \\
\hline November 2003 & $\begin{array}{l}\text { National Council for Science and Technology } \\
\text { reviews and approves research. Study } \\
\text { approved by Kenyatta National Hospital Ethics } \\
\text { and Research Committee }\end{array}$ \\
\hline February to April 2004 & $\begin{array}{l}\text { Administration of quantitative survey } \\
\text { interviews }\end{array}$ \\
\hline June to August 2004 & $\begin{array}{l}\text { In-depth interviews and ethnographic } \\
\text { observations }\end{array}$ \\
\hline August 2004 & Second study advisory committee meeting \\
\hline September 2004 & Data interpretation meeting with MSM \\
\hline
\end{tabular}

In addition to seeking ethical approval, the study established a local study advisory committee (SAC) to advise the research. The SAC included representatives of several key stakeholder organizations, including NASCOP, the University of Nairobi, USAID, Family Health International (FHI), KANCO, and Liverpool VCT Centre. Members of Ishtar and Galebitra were also represented on the committee. Members of the SAC were periodically consulted at various times over the course of the study, and there were two formal meetings of the committee. The first meeting took place in July 2003 to plan and discuss the study protocols and data collection instruments; the second meeting took place in August 2004 to review the findings of the quantitative survey, discuss the ongoing qualitative data collection, and discuss dissemination strategies.

\section{Risk management}

The four-man interview team was trained over a two-week period, during which considerable focus was placed on sensitizing them to issues relevant to the research such as sexuality, stigma and discrimination, and confidentiality. Interviewers were also given a careful orientation on the research objectives, methods, and procedures, and were briefed by members of Ishtar and Galebitra about their organizations. In addition, special emphasis was placed on the careful administration of the survey in order to protect confidentiality and minimize embarrassment or discomfort, given the highly sensitive subject matter.

IAS staff supervised all research activities, and a primary investigator was always available for emergency consultation by the interview team. 


\section{Hgrizons}

\section{Confidentiality}

Although the interview and data entry team were thoroughly trained on the importance of confidentiality, other procedures were implemented to further protect the trust and welfare of the respondents. No personal identifiers were recorded, and the paper questionnaires were securely stored in an undisclosed location. Access to the electronic data, as well as printouts of preliminary results, were limited and subject to the discretion of the research team.

\section{Health issues}

The study team anticipated that some MSM informants might report medical symptoms that would require immediate attention. In these situations, the interviewers were instructed to refer the respondent to the study coordinator. The respondents were then linked to a confidential service provider for treatment, and vouchers were provided for payment of services. During the research activities, the interviewers made 25 referrals and 15 men received diagnostic, treatment, and/or counseling services; the others left before being seen by the doctor or did not show up for services.

\section{Informed consent}

Seeking informed consent was a multi-stage process. Leaders of organized MSM groups were first consulted about the study and asked for their support to identify and approach prospective participants. The study team did a lot of networking at the group and individual level to build trust and enlist support for the study.

All individuals who agreed to participate in the study gave informed consent. The interviewers read the consent statement to the respondent and recorded their agreement to participate. This process followed the recommendations made by the ethical review committees and the Ethical Guidelines on Human Participant Protections issued by the National Institutes of Health (2002). 


\section{Methodology}

\section{Study Design}

Because of the paucity of information on MSM in Nairobi, the study was exploratory and descriptive. Three data collection activities were used: (1) a quantitative survey of MSM; (2) indepth interviews with MSM, gatekeepers, and service providers; and (3) ethnographic observations in MSM social settings. The quantitative survey was implemented first in early 2004 , followed by in-depth interviews and observations (Table 2).

Table 2 Data collection activities

\begin{tabular}{lcc}
\hline & Dates & Number \\
\hline Quantitative survey & February to April 2004 & 500 interviews \\
In-depth interviews with MSM & June to August 2004 & 57 interviews \\
In-depth interviews with gatekeepers & June to August 2004 & 22 interviews \\
In-depth interviews with service providers & July to August 2004 & 11 interviews \\
Ethnographic observations & February to August 2004 & 10 sites \\
\hline
\end{tabular}

\section{Quantitative survey}

Respondents were eligible to be interviewed for the survey if they had a history of having sexual intercourse with one or more male partners. There was no time specification for when this sexual contact was to have last taken place. Individuals were only eligible if they were 18 years of age or older and Kenyan citizens. The age requirement was intended to preclude any ethical issues surrounding the interviewing of minors. Formative assessments indicated a sizable population of foreign MSM in Nairobi, both residents and tourists. Given that an objective of the study was to inform and strengthen local health care services — of which local Kenyans are the primary usersthe decision was made to exclude foreign MSM from the research activities. The study population also included current residents of Nairobi city, although there was no criterion for length of residency. There were no exclusions based on ethnicity, socioeconomic status, or occupation.

The survey questionnaire was made up of six sections on the following broad subject areas: sociodemographic characteristics, stigma and discrimination, sexual practices, knowledge of STIs and HIV, knowledge of/access to services, and social networks. Pre-testing of the questionnaire was done in the city of Mombasa over a two-day period. The pre-testing was very beneficial in allaying the fears and concerns of the interviewers, who were unfamiliar with the general MSM population and were worried about asking some of the detailed questions about sexual practices. The median interview time for the finalized questionnaire was 50 minutes. Questionnaire data were entered using EpiData 3.02 and analyzed using SPSS 11.5 and Stata 6. 


\section{Hgrizons}

\section{In-depth interviews}

In-depth interview respondents were a subset of survey respondents. They were purposively selected by the research team to represent a variety of socioeconomic backgrounds and because they expressed an openness in talking about their lives and experiences. Topics covered by in-depth interviews included sexual practices, behavior change, condom and lubricant use, partner relations, sexual and social networks, and access to treatment and care. The in-depth guides were tested in Mombasa, in conjunction with the survey pre-test.

The quantitative survey provided information on frequently utilized facilities where MSM seek STI treatment and HIV counseling. Providers from these "MSM-preferred" facilities were identified and asked to participate in in-depth interviews. Some of the providers were selected because of their familiarity with or experience in treating MSM. Eleven health service providers were interviewed about their experiences in providing STI treatment and HIV counseling to MSM, their awareness/knowledge of MSM-specific symptoms and health needs, and their attitudes toward MSM.

Gatekeepers are defined as individuals who are in jobs/employment that put them in routine social and/or professional contact with MSM during the course of their duties. Occupations of typical gatekeepers include masseurs, hairdressers, musicians, taxi drivers, tour operators, and hotel/restaurant staff. A gatekeeper may or may not be an MSM. Gatekeepers were interviewed to learn more regarding (a) their interactions with MSM, (b) activities that MSM engage in, and (c) whether their premises could be used to provide interventions to MSM.

\section{Ethnographic observations}

Ethnography of MSM in Nairobi was conducted over a period of six months, which served the dual purpose of establishing trust with MSM and gaining insight into the context of MSM sexual cultures in Nairobi. Several researchers have identified this process as a critical component of behavioral research (Ellen 1984; Parker et al. 1990; Parker et al. 1991; Varga 2000). In-depth data were gathered on the identities and social and interpersonal dynamics that determine the sexual behavior of MSM.

Repeated observations were recorded in 10 sites in different social settings, including pubs, restaurants, massage parlors, discotheques, taxi bays/hubs, and public parks, and were identified during the initial preparatory fieldwork for the survey. Observations were conducted to better understand the everyday activities of MSM in these areas and to gather information on social interactions among MSM. Two research assistants conducted these observations. The emphasis was on an emic approach: understanding MSM in context and discovering how individual MSM view their own situation. Fieldwork largely consisted of having informal conversations, listening to others' conversations, and watching interactions. 


\section{Sampling methods}

As is the case elsewhere, MSM in Nairobi are difficult to identify (Mackay 2001) because of the widespread stigmatization and criminalization of homosexual behavior. Although specific areas or "meeting points" for MSM were informally identified, this study purposely avoided the systematic documentation or mapping of these locations. The research team had previously assured MSM that information on their whereabouts would not exist in any documentation, and therefore could not be obtained by any malicious parties. Although a mapping exercise would have aided the research team in constructing a more scientific sampling frame for the quantitative survey, this mapping would have adversely affected the study by alienating potential MSM informants.

After considering these issues, the researchers decided to use snowball sampling for the quantitative survey. The original target sample size was set at 300 , based on a previous snowball sample survey of MSM in Dakar, Senegal, which achieved 250 interviews (Niang et al. 2003). Two MSM "mobilizers" were identified and asked to notify and recruit respondents for the quantitative survey. After respondents were finished with the questionnaire, they were asked by the interviewers to encourage other MSM they knew to come to a central location at the University of Nairobi to be interviewed.

To compensate for any loss of income that participating in the lengthy interview process entailed and to help with transportation costs to the interview location, respondents were given 500 Kenya shillings (KSH) for their participation. ${ }^{2}$ Because some respondents were poor, the study team anticipated that some participants might attempt to complete multiple interviews. MSM respondents were informed of the importance of interviewing only once and of providing truthful answers. Survey candidates were also asked to wait in a room before being interviewed so that the interviewers could easily identify anyone who had been previously interviewed.

The snowball recruitment strategy proved to be very successful, and after two weeks it was apparent that the target sample size of 300 would be easily achieved. The study team decided to increase the sample size to 500, which would help increase the representation of certain MSM groups who were not easily mobilized to come to the university. ${ }^{3}$ Plans were made to arrange interviews at outside locations such as massage parlors, hair salons, and hotels. By the end of the surveying period, 39 of the 500 interviews had been conducted at outside venues (Table 3). Among the men who came to the university to be interviewed or who were approached at outside venues, none refused to participate in the study.

\footnotetext{
${ }^{2}$ About US\$6.50. The week before the interviews were conducted, new Kenyan government regulations took effect, requiring public transportation vehicles to meet rigid safety standards. As a result, cheap public transportation was scarce during the first weeks of interviewing, and some MSM may have had to use a taxi for transport to the interview.

${ }^{3}$ An amendment to the study protocol was submitted to the Kenyatta National Hospital Ethics and Research Committee, and the sample size increase was approved.
} 


\section{Hgrizons}

Table 3 Locations of quantitative survey interviews

\begin{tabular}{lcc}
\hline Location & Number of sites & Number of interviews \\
\hline Institute of African Studies_University of Nairobi & 1 & 461 \\
Massage parlors & 2 & 13 \\
Taxi hub $^{*}$ & 2 & 11 \\
Hair salons & 3 & 7 \\
Hotels & 2 & 7 \\
Restaurants & 1 & 1 \\
Total & $\mathbf{1 1}$ & $\mathbf{5 0 0}$ \\
\hline
\end{tabular}

*Taxi hubs are public locations where multiple taxi drivers traditionally wait for customers.

\section{Study Limitations}

The study team acknowledges the limitations of snowball sampling; the findings from this sample may not be representative of all MSM in Nairobi. MSM who are married, have professional jobs, and are Kenyan citizens of European and Indian ethnicity were the most difficult to recruit, and therefore may be underrepresented in the survey. Although foreign MSM were purposely not included in the study, there may be important behavioral interactions between foreign and Kenyan MSM that the study did not address adequately.

Also, a few MSM may have managed to bypass the interviewer recognition checks in an effort to receive the compensation for an extra interview. A review of the data, however, does not indicate any obvious occurrences of repeat interviews.

Because HIV or STI testing was not performed in this study, it was not possible to determine the impact of the HIV epidemic on MSM in Nairobi; it was also not possible to explore the dynamics of HIV/STI transmission between MSM and the general population. 


\section{Results}

\section{Profile of Respondents}

Although the survey sample of 500 MSM represented a wide age range (18-55), the sample was relatively young; 91 percent of respondents were 35 years or younger and the median age was 26 . The study team recruited a substantial number of university students throughout the Nairobi area, which may have contributed to skewing the median age to a lower figure. (Figure 1 for the age distribution of respondents.) Most respondents were long-term residents of Nairobi. Fifty percent of the respondents had lived in Nairobi 10 years or longer and 22 percent had lived in Nairobi their entire life.

\section{Figure 1 Age of survey respondents}

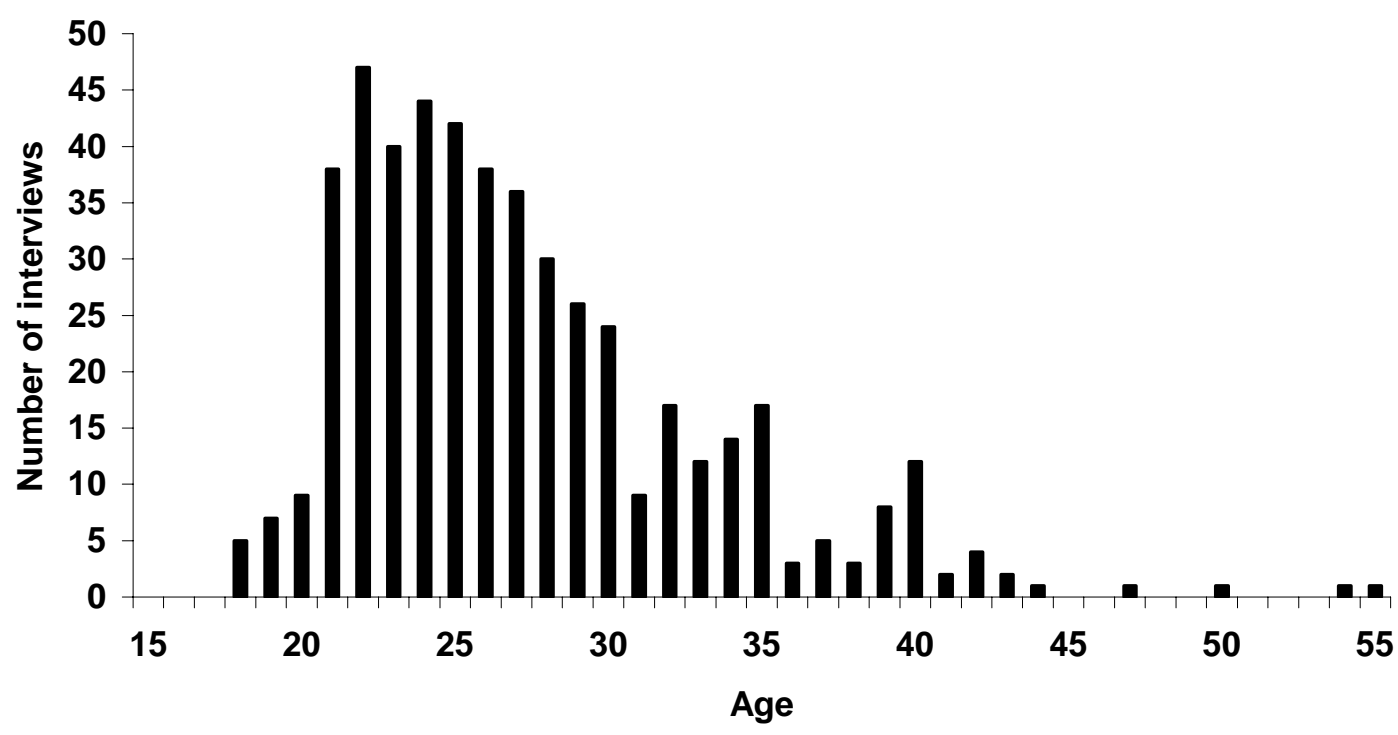

Respondents were from diverse socioeconomic backgrounds, ranging from the unemployed to educated professionals. Respondents who had no occupation ( 15 percent), students ( 21 percent), and sex workers (14 percent) were the easiest employment subgroups to classify. The remaining 50 percent of respondents reported a wide variety of professions, jobs, and activities by which they earned income. For analysis, the research team classified these respondents into three categories. The first category — small-scale earners (16 percent) — had jobs/activities that provided limited income on an irregular basis. Reported jobs in this category included casual laborers, hawkers, marketers, street salesmen, and kiosk operators. The second category-professional or steady income earners (15 percent) - represented respondents who had regular employment regardless of the economic status of their job. This included professional positions such as bankers and businessmen, as well as labor-oriented jobs such as factory workers, store clerks, or petrol station attendants. The third category is an extension of those who have regular employment, but are in a particular profession that is more likely to put them in close or regular contact with MSM. Results 


\section{Hgrizons}

from the in-depth interviews and ethnographic observations showed that respondents with these "gatekeeper/close-contact" jobs (19 percent) were more likely to knowingly interact with MSM in the course of their professional duties. Occupations in this category included masseurs, hairdressers, musicians, taxi drivers, tour operators, and hotel/restaurant staff. These six occupation categories were represented fairly equitably in the survey (Figure 2), despite the limitations of the snowball sampling methodology.

Figure 2 Occupation categories

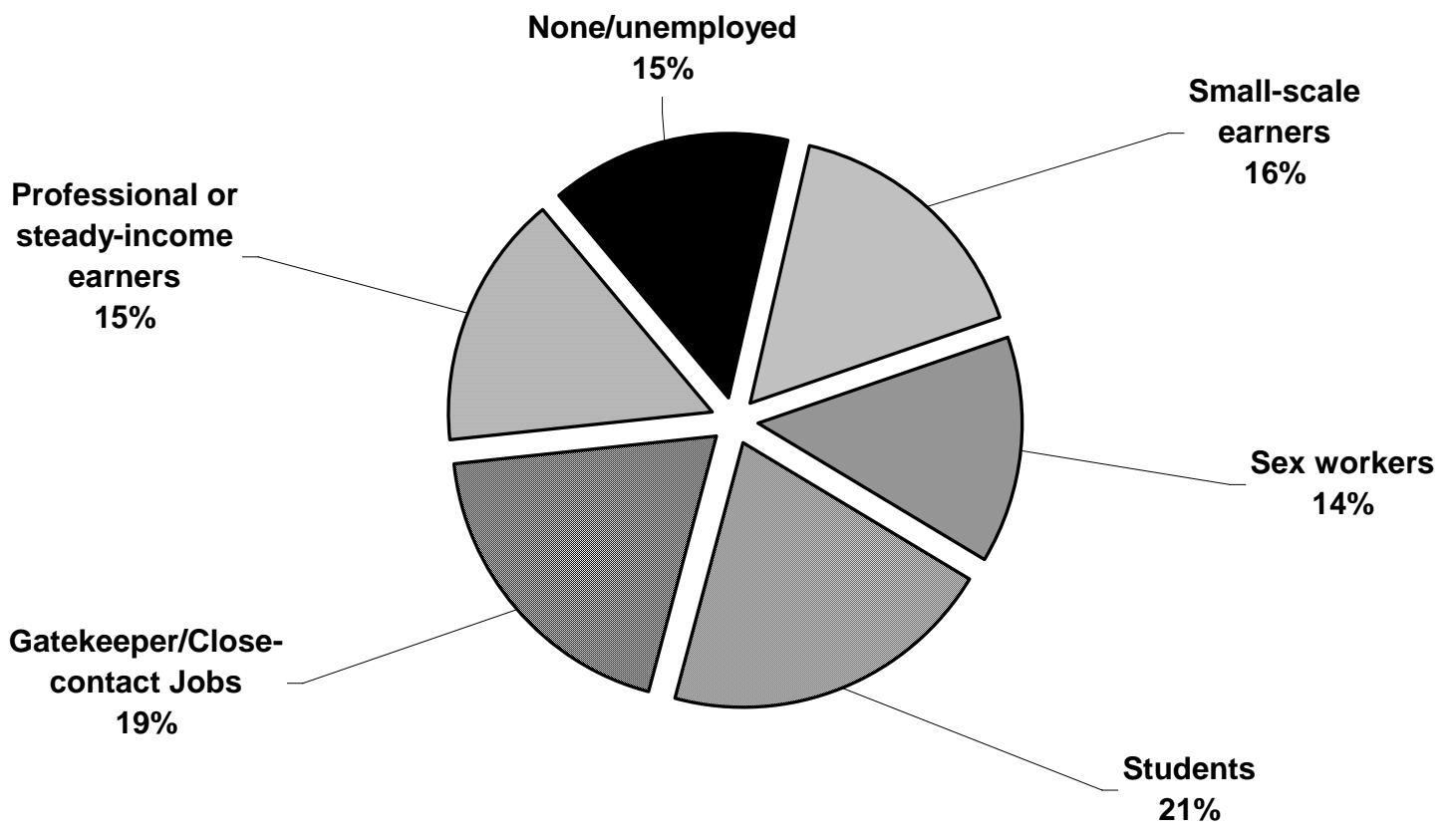

The sociodemographic profile revealed diverse characteristics among the sample (Table 4). Respondents were fairly well educated, with 69 percent having completed secondary school or higher. Most of the respondents reported being Christian, evenly divided between 45 percent Protestants and 44 percent Catholics. The ethnicity of MSM respondents also reflected the pattern of the general population of Nairobi, with the majority claiming to be Kikuyu (40 percent), followed by Luo (19 percent), Luhya (16 percent), and Kamba (12 percent). There were several other reported ethnicities, although none of these groups represented more than 3 percent of interviewees.

The survey confirmed that many MSM had either current or past sexual relationships with women. Some of the respondents reported being currently married to a woman ( 7 percent), and a similar number of respondents were divorced, separated, or widowed ( 7 percent). Besides the 14 percent who reported a marital history, other respondents indicated past sexual relationships with women. These men were among the 22 percent who reported having at least one child. The median number of children reported by these respondents $(n=108)$ was one, with nine percent having three or more children. 
Table 4 Sociodemographic profile of respondents $(n=500)$

\begin{tabular}{|c|c|}
\hline Median age & 26 years \\
\hline & $\%$ \\
\hline \multicolumn{2}{|l|}{ Length of residency in Nairobi } \\
\hline 5 or less years & 28 \\
\hline 6 to 10 years & 22 \\
\hline 11 to 20 years & 22 \\
\hline Over 20 years & 27 \\
\hline \multicolumn{2}{|l|}{ Religious denomination } \\
\hline Protestant & 45 \\
\hline Catholic & 44 \\
\hline Muslim & 5 \\
\hline No religion & 5 \\
\hline Others & 1 \\
\hline \multicolumn{2}{|c|}{ Highest education level completed } \\
\hline None & 9 \\
\hline Primary & 21 \\
\hline Secondary & 46 \\
\hline College or university & 23 \\
\hline \multicolumn{2}{|l|}{ Ethnicity } \\
\hline Kikuyu & 40 \\
\hline Luo & 19 \\
\hline Luhya & 16 \\
\hline Kamba & 12 \\
\hline Others (less than $3 \%$ each) & 13 \\
\hline \multicolumn{2}{|l|}{ Marital status (with women) } \\
\hline Single & 86 \\
\hline Married & 7 \\
\hline Divorced & 3 \\
\hline Separated & 2 \\
\hline Widowed & 1 \\
\hline Have at least 1 child & 22 \\
\hline
\end{tabular}

\section{Sexual I dentities}

Given that a sizable proportion of MSM in the sample has a history of marriage or sexual relationship with women, it is important to understand the sexual context of MSM relationships. The term "men who have sex with men" encompasses a broad range of potential sexual roles and identities. For example, there are situations where a man does not identify himself as "gay" or "homosexual," yet has sexual intercourse with another male (UNAIDS 2000). 


\section{Hgrizons}

Survey respondents were asked how they would describe their sexual identity in their own words. The most commonly stated terms were English-language ones: gay (46 percent), bisexual (23 percent), and homosexual (16 percent). Another 12 percent used a local language word-shoga (12 percent). Qualitative research revealed that shoga is a Kiswahili word meaning gay or homosexual. While respondents note that many MSM in Kenya use the term freely among themselves, many consider shoga to be a vulgar word. As used by non-MSM in the general population, shoga can be interpreted as strongly derogatory and insulting.

Respondents who identified themselves as shoga were significantly more likely than other MSM respondents to have had no education (44 percent to 5 percent, $\mathrm{p}<0.001$ ). Among the broad employment categories (Table 5), only the unemployed, small-scale earner, and sex worker groups had substantial numbers identifying themselves as shoga. The use of shoga as a self-descriptive sexual identity is associated with MSM of lower socioeconomic status in Nairobi, and may reflect that some men who identify as shoga do not speak English. Qualitative data does not indicate that shoga has connotations that would distinguish it greatly from the English terms gay or homosexual. Basha is a slang term used to refer to persons who play the receiver (passive) role during sexual intercourse. Few men identified themselves as basha $(n=5)$ or transsexual $(n=2)$.

Table 5 Self-reported sexual identities, by occupation category

\begin{tabular}{|c|c|c|c|c|c|c|c|}
\hline & \multicolumn{7}{|c|}{ Occupation category } \\
\hline & $\begin{array}{l}\text { Nonel } \\
\text { unemployed } \\
\qquad \begin{array}{c}n=73 \\
\%\end{array}\end{array}$ & $\begin{array}{c}\text { Small- } \\
\text { scale } \\
\text { workers } \\
\text { n = 81 } \\
\%\end{array}$ & $\begin{array}{c}\text { Sex } \\
\text { workers } \\
\begin{array}{c}n=69 \\
\%\end{array}\end{array}$ & $\begin{array}{l}\text { Students } \\
\begin{array}{c}n=103 \\
\%\end{array}\end{array}$ & $\begin{array}{c}\text { Gatekeeperl } \\
\text { close- } \\
\text { contact } \\
n=96 \\
\%\end{array}$ & $\begin{array}{c}\text { Steady } \\
\text { wage- } \\
\text { earners } \\
n=77 \\
\%\end{array}$ & $\begin{array}{c}\text { Total } \\
\text { n = } 499 \\
\%\end{array}$ \\
\hline Gay & 52 & 25 & 30 & 63 & 49 & 49 & 46 \\
\hline Bisexual & 11 & 19 & 12 & 25 & 30 & 35 & 23 \\
\hline Homosexual & 11 & 30 & 16 & 8 & 19 & 14 & 16 \\
\hline Shoga & 22 & 20 & 38 & 1 & 2 & 0 & 12 \\
\hline Others* & 4 & 7 & 4 & 3 & 0 & 1 & 3 \\
\hline
\end{tabular}

*Includes basha and transsexual

The 23 percent of respondents who reported themselves as bisexual were represented in all occupation categories, and nearly all men who identified as bisexual $(\mathrm{n}=114)$ had ever had sex with a woman ( 99 percent). History of sexual activity with females was not exclusive to bisexuals, however, as 69 percent of homosexuals $(n=80), 55$ percent of gays $(n=229)$, and 61 percent of shoga $(\mathrm{n}=61)$ had ever had sex with a woman. Self-identified bisexuality in the qualitative interviews was often associated with occasional emotional relationships with women, but could also reflect relationships of convenience. These included marital relationships used to cover up the secret lifestyle of a MSM, as well as situations in which women provide economic support to the man in exchange for a sexual relationship. The emotional aspects were particularly evident in students, some of whom stated that they were still exploring their sexuality. 
Results show that at least half of respondents had their first sexual encounter with a male (Table 6), while about 42 percent had their first sexual experience with a female. The median ages of first sexual encounters with males and females are respectively $17(\mathrm{n}=500)$ and 16

$(\mathrm{n}=331)$ years. Reported first male sexual partners were mostly close acquaintances such as fellow students (44 percent), neighbors (13 percent), or friends/social acquaintances (12 percent). Five percent reported sexual initiation with a prison inmate. Even fewer respondents reported having their first male sexual encounter with a foreigner or tourist ( 3 percent). Of those respondents who reported a first male sexual experience with a fellow student $(n=222), 85$ percent were 18 years or younger at the time (median age 16). The survey data are consistent with qualitative findings, which indicate that many in-depth interviewees experienced - or started exploring - sex with men during adolescence. There was no question in the survey or in the in-depth interviews that explored whether these first experiences with males were consensual or nonconsensual encounters.

Table 6 Sexual initiation with men and women $(n=500)$

\begin{tabular}{lc}
\hline Median age of first sexual experience with a male & 17 years \\
Has ever had sex with a female & $69 \%$ \\
Median age of first sexual experience with a female $(\mathrm{n}=331)$ & 16 years \\
\hline & $\%$ \\
\hline Sex of first sexual partner* & 50 \\
Male & 42 \\
Female & 5 \\
Male and female at same age & 3 \\
Undetermined (Could not remember at least one age, or missing data) & \\
First male sexual partner & 44 \\
Fellow student & 13 \\
Neighbor & 12 \\
Friend or social acquaintance & 9 \\
Relative & 5 \\
Prison inmate & 4 \\
Stranger or client & 3 \\
Teacher & 3 \\
Foreigner or tourist & 3 \\
Employer or co-worker & 3 \\
Other & 4 \\
\hline
\end{tabular}

${ }^{*}$ Calculated from separate reported ages of first male/female sexual encounters

Social and economic factors play an important role in shaping the sexual behavior and identities of MSM in the study. According to survey respondents, pleasure ( 52 percent) or love ( 22 percent) is what they are most looking for when they have sex. For another 20 percent of respondents it was financial support. Qualitative findings confirmed that the reasons for first having - and continuing to have- - sexual relationships with men are varied. 


\section{Hgrizons}

"I have a regular male partner with whom I usually practice sex. I also have a woman who is my permanent partner. With men I am very satisfied sexually...but for women I do it for the sake of doing it, and I do not enjoy it."

Tour guide, 36 years old

"I was in high school when I met a very handsome boy fellow student who I was so attracted to. We became very close friends then I mentioned to him that I was sexually attracted to him. He was very happy...."

College student, 22 years old

"I am attracted to both men and women... it is an advantage to be in love with both."

Hairdresser, 32 years old

\section{Social Networks}

Given their fear of stigma and violence, it is not surprising that many MSM (36 percent) have not discussed their sexual orientation with another person (Figure 3). Most relied on their networks of fellow MSM, sexual partners, and friends (64 percent); far fewer discussed MSM behavior with family members, other acquaintances, and/or health care personnel. A majority of MSM (68 percent) reported being "uncomfortable" discussing sexual practices with anyone who is not a male sexual partner.

Findings show that the communication networks of MSM in the sample were different from their living situations (Figure 3). Whereas 35 percent of MSM live with a family member, only 3 percent discussed their sexual lives with family. Only 20 percent reported that members of their family were aware of their sexual orientation, and fewer (12 percent) stated that family members were aware of - and accepted - their sexuality.

Figure 3 Discussion networks and living situations

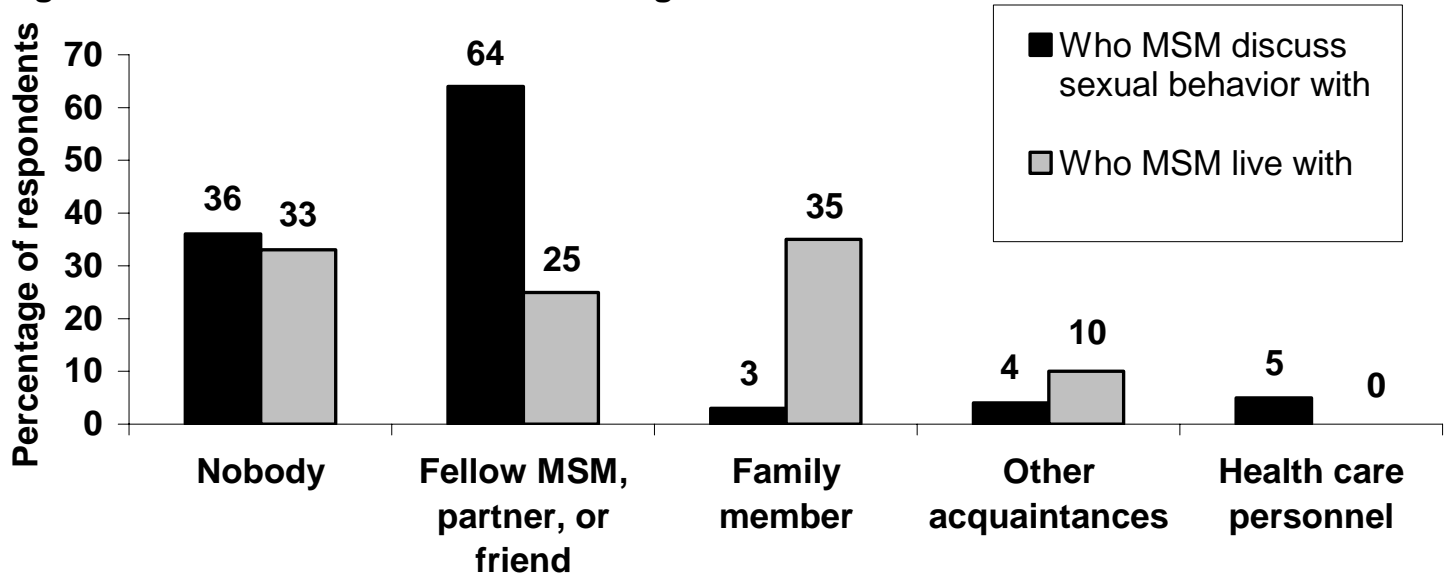

Note: Percentages may not add to 100 percent, as multiple responses were possible. 
Many MSM appear to have responded to the lack of family and professional support by developing strong personal networks with each other. The "hubs" of these personal support systems are typically informal social groups of various sizes, often associated with the physical/geographical location in which they tend to socialize. These locations include parks, bars, and restaurants; many MSM freely move between these locations. Information is capable of traveling quickly through these networks by "word-of-mouth" and cheap text messages via mobile phones, as evidenced by the rapid success of snowball sampling during the course of the quantitative survey.

In-depth interviews with gatekeepers confirmed that MSM individually and in groups choose their locations for socialization carefully to protect themselves from exposure. This qualitative information reveals that while MSM maintain a low profile, they are still identified easily by gatekeepers who do business with MSM.

"Most of the time we receive MSM clients. I have two different... places; of which one we receive mostly whites, and the other one for everyone. Most of the MSM clients frequent the [establishments] during the day and some in the evening."

Business owner

A taxi driver confirmed dealing with local MSM as well:

"I have a large number of MSM clients. Sometimes I work during the day and receive them. In the evening they start coming as early as $8 \mathrm{pm}$. Sometimes they rent the car in a group of four MSM clients.”

Taxi driver

In addition to informal social connections, 22 percent of MSM respondents consider themselves members of an MSM group within Kenya. Some of these are social groups that engage purely in leisure activities; others are advocacy-based groups with clearly defined organizational systems and missions. Ishtar and Galebitra are groups from the latter category. Research reveals, however, that the influence of these advocacy groups is limited, as only 16 percent of respondents were aware of Ishtar, 5 percent of Galebitra, and 2 percent each of Tommick and Bazobana.

Many respondents have strong connections to society in general. Many are affiliated with nonMSM groups, including 19 percent with sports associations, 14 percent with religious groups, and 11 percent with community-based organizations (CBOs) or non-governmental organizations (NGOs). Many MSM also possess documents such as national ID cards (92 percent), voter cards (59 percent), bankcards or passbooks (40 percent), driver's licenses (33 percent), and passports (25 percent).

Although many participate in society, MSM continue to rely on each other for emotional and material support. Over 90 percent of MSM "agreed" that they could count on each other for financial support, moral or emotional support, temporary housing assistance, accompaniment to a health care provider, and assistance in violent situations. Many MSM discuss their personal problems with each other ( 72 percent). Table 7 shows that stigma and discrimination was the problem discussed by the greatest number of respondents ( 63 percent). 


\section{Hgrizons}

Table 7 Five most discussed problems among $\operatorname{MSM}(n=500)$

\begin{tabular}{ll}
\hline Problems discussed $^{*}$ & $\%$ \\
\hline Stigma and discrimination & 63 \\
Financial and/or employment issues & 32 \\
STIs/HIVIAIDS (in general) & 30 \\
STI and HIV prevention behaviors & 29 \\
Human rights & 28 \\
\hline
\end{tabular}

*Multiple responses allowed

\section{Stigma, Discrimination, and Violence}

MSM perceive stigma and discrimination to be a major problem in their everyday lives. Many MSM in the sample believe they are rejected and hated by the general society, and feel that they must take great care to avoid revealing their sexual identities. However, some MSM are more open about their sexual orientation in social settings.

Survey respondents were asked if they had experienced any forms of stigma, discrimination, or violence during the previous twelve months. Reported incidents of stigma/discrimination and violence indicate that MSM are at greatest risk in public areas. Overall, incidents of stigma/discrimination were reported by 33 percent of respondents; aggression and humiliation in public areas were the most common types of stigma/discrimination whereas other incidents were comparatively rare (Table 8).

Table 8 MSM experiencing stigma, discrimination, and violence in past 12 months $(n=500)$

\begin{tabular}{lr}
\hline & $\%$ \\
\hline Forms of stigma/discrimination experienced (any form) & 33 \\
Aggression and/or humiliation in public & 26 \\
Alienation/harassment by family/friends/neighbors & 8 \\
Discrimination in the work place & 6 \\
Refusal of service & 3 \\
Eviction/expulsion from place of residence & 1 \\
Other & 2 \\
Forms of violence experienced (any form) & 22 \\
Verbal & 14 \\
Physical & 12 \\
Sexual & 5 \\
Other & 4 \\
\hline
\end{tabular}

Note: Percentages may not add to 100 percent, as multiple responses were possible. 
Violence was experienced by 22 percent, with verbal abuse (14 percent) and direct physical abuse (12 percent) among the types of incidents that were reported. It was also found that 5 percent reported sexual violence, and 14 of 25 of these victims were sex workers. Interestingly, perpetrators of violence were most frequently identified as partners, colleagues, friends, or clients. When asked why many violent incidents originate from their peers, one MSM participant at the 2004 data interpretation meeting responded: "Well, we are a family... and families do have quarrels." Data from in-depth interviews and ethnographic observations reveal that violence between sex workers often stemmed from competition over potential clients or partners.

Analysis by occupation reveals that self-identified sex workers are at higher risk of stigma/discrimination and violence (Figure 4). Sex workers were significantly more likely than other MSM to report stigma/discrimination (59 percent to 29 percent; $p<0.001$ ) and violence (39 percent to 19 percent; $p<0.001)$. Qualitative data revealed that sex workers are often more visible in public places because they are attempting to attract clients. This places them in more vulnerable situations and locations, which other MSM are more likely to avoid.

\section{Figure 4 Percent reporting stigma and violence in last 12 months}

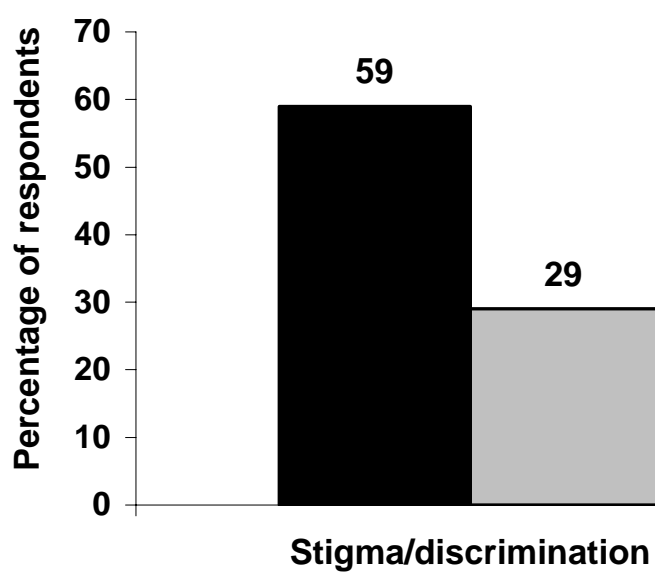

Sex workers $(n=69)$ $\square$ Other MSM ( $\mathrm{n}=431)$

39

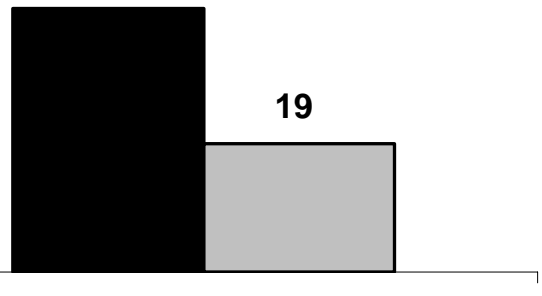

Violence

MSM who are sex workers are often in the company of female sex workers in social places to mask their identities from both the ordinary public and the police. Ethnographic observations revealed a well-nurtured symbiotic relationship between male and female sex workers where both parties benefit from "hanging out" together in search of clients. This enables MSM to conceal their sexual identities from the suspecting public while also protecting female sex workers from police harassment and arrest on prostitution charges.

Given that the majority of MSM perceive stigma to be a major problem, it is important to contextualize how stigma impacts their lives. Qualitative interviews revealed that realized events of stigmatization are not as much a problem as is the unrealized threat of public exposure. MSM in the sample are very fearful of how friends, family, neighbors, the public, and the law would react to knowledge of their sexual identities. Efforts to "mask" their sexual behavior include extreme 


\section{Hgrizons}

discretion in their social conduct. Some men will also have relationships with women-including marriages - to help hide the fact that they are also sexually active with men.

"I have had different (male) sexual partners but not permanent partners.... Most of my (male) partners are married just like me. I do not like having a permanent partner for fear of my wife finding out the truth."

Self-employed respondent, 40 years old

The efforts of MSM to hide their sexual identities may have a protective effect by limiting exposure to actual abuse and harassment. The psychosocial effects of stigmatization and discrimination, however, may prevent them from seeking MSM-specific knowledge and health care that would be important in preventing HIV and STI transmission.

\section{Knowledge of HIV and STIS}

By 2004, there had been a high level of effort by the Government of Kenya (GOK), multi- and bilateral organizations, NGOs, and CBOs to educate the Nairobi public on HIV transmission. Findings from the survey revealed that all respondents were aware of HIV/STIs and had received information in the past. When asked where they last obtained any information on HIV/STIs, the most cited sources were television, radio, or discussion with peers (Table 9). Nearly two thirds (64 percent) reported "ever attending" a group discussion/session on HIV and STIs.

Table 9 Where MSM last received information about STIs and HIVIAIDS $(n=500)$

\begin{tabular}{lc}
\hline Source of information & $\%$ \\
\hline Television & 24 \\
Radio & 24 \\
Discussion with peers & 20 \\
VCT centers/health centers/hospitals & 7 \\
Newspapers & 7 \\
NGO/CBO & 7 \\
Conference/seminar/church/group meeting & 6 \\
MSM partner & 2 \\
Other & 4 \\
\hline
\end{tabular}

The high level of access to information - and participation in group discussions - raises the question of whether MSM are receiving and sharing correct information about HIV. When asked to identify methods of HIV transmission, 94 percent of MSM knew correctly that HIV is transmitted via "unprotected sex" (Table 10). However, 12 percent cited incorrect or negligible means of transmission including kissing, sharing toothbrushes, and mosquito bites.

A few men in the survey (1 percent) of MSM specified that HIV can only be transmitted via vaginal sex - protected or unprotected. Qualitative interviews confirmed that some MSM believe 
incorrectly that HIV is not transmitted via anal intercourse, and is transmitted only through women. These MSM typically believed that vaginal sex was the "...riskiest" type of sex because of the amount of fluids involved as compared to anal sex.

"Vaginal sex is like swimming in a pool of water [fluids], which increases the risk of HIV transmission."

Unemployed respondent, 29 years old

When asked how someone can avoid HIV/STIs, 77 percent of respondents cited consistent use of condoms. A high number of respondents also reported abstinence (53 percent) and faithfulness to a partner (42 percent) as prevention strategies (Table 10).

Table 10 Knowledge of HIVISTI transmission and prevention $(n=500)$

\begin{tabular}{lc}
\hline & $\%$ \\
\hline Reported methods of HIV transmission* & 94 \\
Unprotected penetrative sex & 80 \\
Exposure to infected blood (via wounds, sharps, needle sharing) & 32 \\
Mother-to-child transmission & 12 \\
Incorrect or negligible risk (e.g., kissing, sharing toothbrushes, mosquito bites) & 8 \\
Vaginal sex with women & 5 \\
Sex with multiple partners & 2 \\
Oral sex & \\
Reported methods of HIVISTI prevention* & 77 \\
Consistent condom use & 53 \\
Abstinence & 42 \\
Faithfulness to partner & 32 \\
Avoiding multiple partners & 14 \\
Correct use of condoms & 5 \\
Good hygiene after intercourse & 3 \\
Medication use & 2 \\
Non-penetrative sex & 2 \\
Use of condoms with unknown partners & 8 \\
Other & 8 \\
\hline
\end{tabular}

*Multiple responses allowed.

Overall, a high number of survey respondents were well informed on HIV/STI transmission and prevention methods. It appears that MSM in the sample have received mostly correct information via media sources, and that this information is being passed on through MSM social networks. In qualitative interviews, 44 of 57 MSM reported discussing HIV transmission with their partners, colleagues, and friends. Their discussions revolved around preventive and protective measures that are responsive to their needs, including condom use, as illustrated by the following quote. 


\section{Hgrizons}

"I normally discuss HIV/AIDS with my partners, especially issues like carrying enough condoms, having trustworthy partners, and sticking to them. I also discuss how to eventually stop commercial sex life."

Male sex worker, 28 years old

\section{Sexual Practices}

The frequency and types of specific sexual acts, the number of partners, and the types of partner relationships are important factors influencing the dynamics of HIV/STI transmission within a particular population. Although anal intercourse is a primary characteristic of MSM sexual behavior in this study, formative research indicated that other sexual practices were common. These included oral sex, nonpenetrative sexual practices, and sexual intercourse with women.

All but two of the 500 respondents had had anal intercourse at least once with another male within the past year. Table 11 shows the percentage of respondents who reported having anal intercourse, nonpenetrative sex, and group sexual encounters by time period.

Table 11 Type of sex by time period $(n=500)$

\begin{tabular}{lccc}
\hline & $\begin{array}{c}\text { Within } \\
\text { past week } \\
\%\end{array}$ & $\begin{array}{c}\text { Within past } \\
\text { month } \\
\%\end{array}$ & $\begin{array}{c}\text { Ever } \\
\%\end{array}$ \\
\hline Anal intercourse (either insertive or receptive) & 61 & 89 & 100 \\
Nonpenetrative sex (any kind)* & 52 & 61 & Not asked \\
Group sex encounters** & 3 & 10 & 25 \\
\hline
\end{tabular}

*Nonpenetrative sex was defined as including oral sex, thigh sex, and/or mutual masturbation.

${ }^{* \star}$ Any sexual encounter with two or more men at the same time.

Almost two thirds of respondents reported having anal intercourse with at least one partner in the past week. Within the past month, 89 percent of respondents reported anal sex with at least one partner. Nonpenetrative sex was also frequently reported, with 52 percent reporting at least one nonpenetrative sex act within the past week and 61 percent within the past month. When asked if their typical sexual practices included oral sex, 63 percent of respondents said yes.

Anal intercourse can potentially place a receptive sexual partner at higher risk of contracting an STI from their penetrating partner. Respondents were asked what role they typically played during anal intercourse with other men. Over half engage in both receptive and insertive anal intercourse, and 28 percent reported usually being insertive partners and 16 percent reported usually being receptive partners. These percentages were consistent with reported types of anal sex practiced within the past month (Figure 5). 


\section{Figure 5 Types of anal intercourse reported in past month}

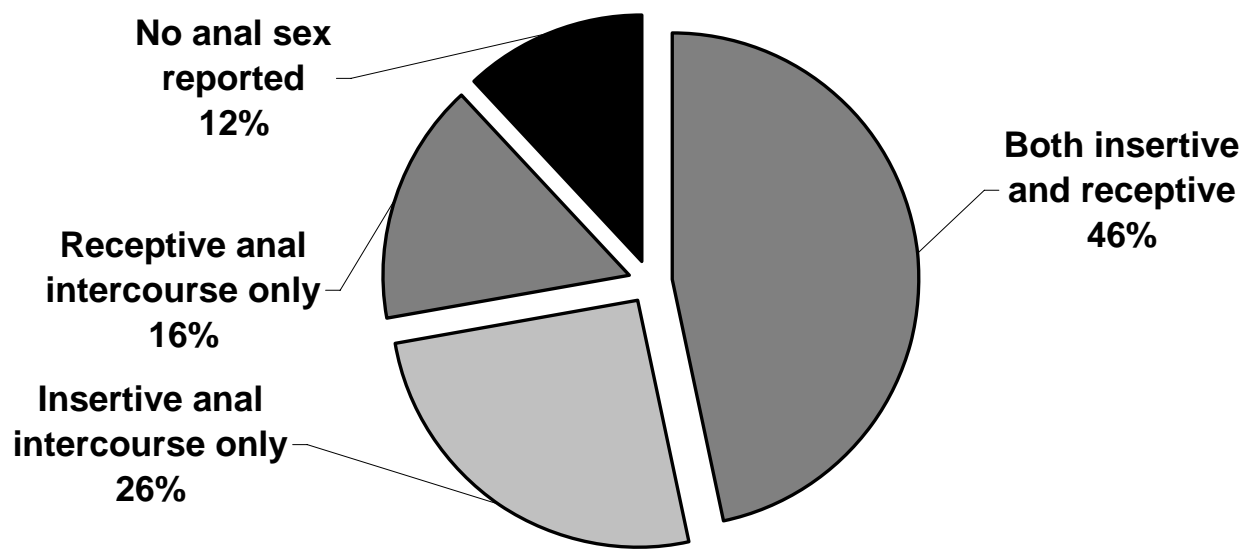

There is a high level of multiple partner activity; 79 percent of MSM have had two or more partners within the past year (Figure 6). The median number of different partners in the past year was three. This may be an underestimation, however, because the calculation of the median of three partners does not factor in the 30 percent of respondents who "could not remember the exact number" of partners. A sizable minority (21 percent) reported only one sexual partner over the past year; 10 percent reported being abstinent in the previous month, and only 2 respondents reported being abstinent for the previous year.

Figure 6 Percent reporting abstinence, monogamy, and multiple partners

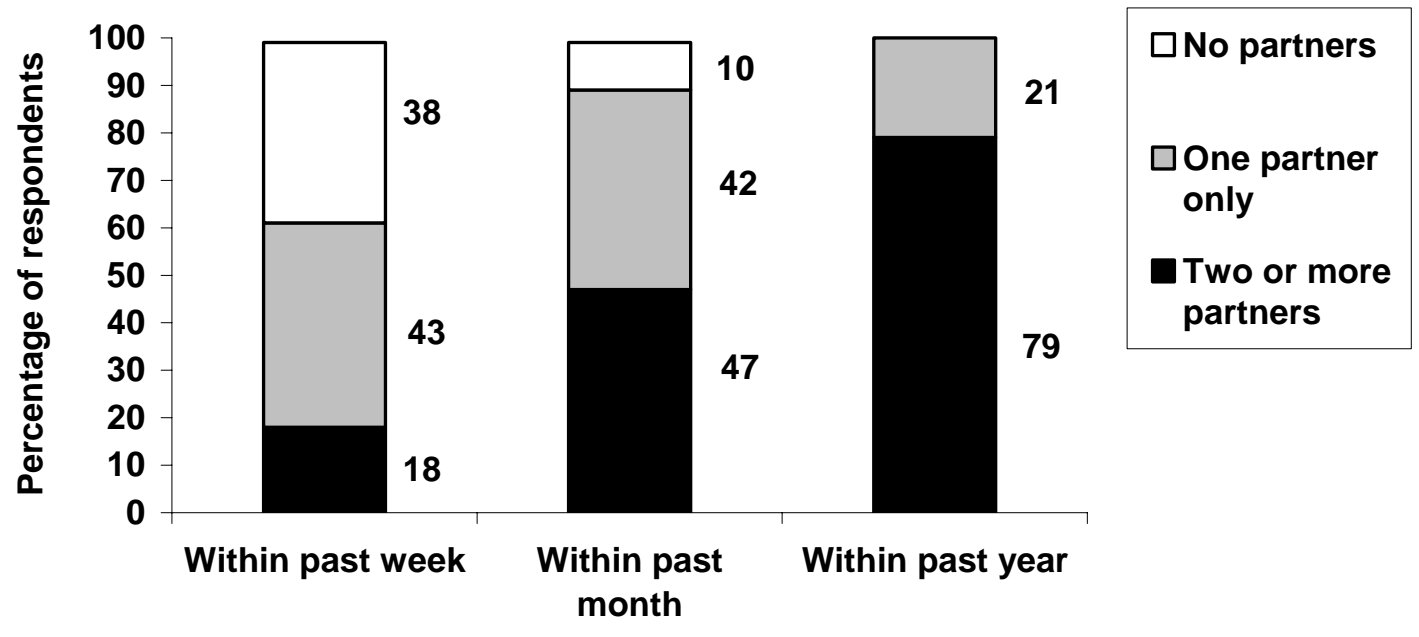

Note: Respondents reporting not remembering "the exact number of partners" were assumed to have at least two partners in the relevant time period. 


\section{Exchange of money and gifts for sex}

Although some respondents specifically identified themselves as sex workers, it was found that the receipt of money and/or gifts for sex is common among all occupational groups (52 percent; Table 12). The gifts given were very diverse, ranging from beers to housing/rent payments. Whereas sex workers were most involved in straightforward exchanges of money for sexual favors, other MSM, particularly those in gatekeeper professions supplement their regular incomes with sex work. There are some masseurs, for example, who provide sex if requested during the course of their regular duties.

Twenty-nine percent of respondents also reported paying for sex. The median amount of money paid the last time was $300 \mathrm{KSH}$ (about US\$3.90). This amount was substantially different from the 52 percent of respondents who reported a median amount received for sex of 1,200 KSH (about US\$15.50). It is possible that foreign MSM and professional Kenyan MSM-groups that were either not surveyed or underrepresented-may account for this difference by being the higherpaying partners of the men in the sample.

Table 12 Exchange of money and/or gifts for sex with men $(n=500)$

\begin{tabular}{cc}
\hline Paid something for sex in the last 12 months & $29 \%$ \\
Median amount of money paid for sex the last time & $300 \mathrm{KSH}$ \\
Received something for sex in the last $\mathbf{1 2}$ months & $52 \%$ \\
Median amount of money received for sex the last time & $1,200 \mathrm{KSH}$ \\
\hline
\end{tabular}

\section{Sex with women}

As mentioned previously, the sexual practices of MSM are not limited to male partners only. Of the MSM who have ever had sex with a female $(\mathrm{n}=344), 20$ percent reported having vaginal intercourse with a woman in the past month (Table 13). Seven percent of respondents who had ever had sex with a female reported having anal sex with a female in the past month. Of the 34 married respondents, 32 were sexually active with their wives within the past year.

Table 13 Percent reporting sex with at least one female partner (of those who have ever had sex with a female)

\begin{tabular}{lcc}
\hline & $\begin{array}{c}\text { Within past week } \\
(\mathbf{n}=\mathbf{3 4 4})\end{array}$ & $\begin{array}{c}\text { Within past month } \\
(\mathbf{n}=\mathbf{3 4 4})\end{array}$ \\
\hline Vaginal intercourse & 10 & 20 \\
Anal intercourse & 3 & 7 \\
\hline
\end{tabular}

Qualitative interviews showed that it is not unusual for MSM to maintain relationships with women and men simultaneously. Some of these MSM engage in both vaginal and anal sex with women. One university student described himself as being "a heterosexual in a homosexual context." MSM 
working in salons also stated during in-depth interviews that they are often pressured by their female clients to engage in sex.

\section{Condom and Lubrication Use}

More than half of MSM (58 percent) reported "always" using condoms for anal sex in the past year; 75 percent reported using a condom during their last anal sex act (Table 14). This was an unexpectedly high result, given that earlier meetings with members of organized MSM groups indicated that condom use among their peers was low. Recent findings from the 2003 Kenya Demographic and Health Survey (CBS, MOH, and ORC Macro 2004), however, indicated that condom use among men in the general Nairobi population is also high. From a DHS subsample of 122 men in Nairobi Province who reported "higher-risk" sexual activity, ${ }^{4} 64$ percent reported using a condom during their last sex act.

Table 14 Percent reporting condom use at last sex with men

\begin{tabular}{ll}
\hline & $\%$ \\
\hline Anal intercourse (either insertive or receptive) & $75(\mathrm{n}=500)$ \\
Insertive anal intercourse only & $72\left(\mathrm{n}=429^{\star}\right)$ \\
Receptive anal intercourse only & $75\left(\mathrm{n}=384^{\star \star}\right)$ \\
\hline
\end{tabular}

*Not including respondents who have never anally penetrated another partner.

**Not including respondents who have never been anally penetrated.

Other survey data from the Nairobi MSM revealed that the ability to negotiate condom use is also high, as 77 percent felt confident that they could get their male partner to agree to use a condom. Condoms are currently widely available around Nairobi, and MSM obtain condoms mainly from neighborhood shops or pharmacies. Less than 5 percent of MSM reported obtaining condoms from health facilities, and none from peer educators. When asked during the survey interviews if they were carrying a condom, 13 percent of respondents said they were and showed one to the interviewer.

Respondents who reported not using condoms during their last anal sex act $(\mathrm{n}=124)$ were asked their reasons for non-use. "Trust" of partners was reported by 51 percent as the most reported reason. "Not liking condoms" (18 percent) and partner refusal to use (11 percent) were other reasons given. Lack of availability ( 7 percent) and affordability (3 percent) were less of a barrier to MSM condom use.

"Never-use" of condoms was reported by 11 percent of respondents. Qualitative data showed that those who "never-use" condoms practiced other methods that they believed were protective but may be less effective as barriers to HIV/STI transmission. One respondent reported:

\footnotetext{
4 "Higher-risk" sex was defined by the DHS as sex with a nonmarital, noncohabitating partner in the past 12 months.
} 


\section{Hgrizons}

“...depending on how you feel about a client, how sweet he looks, talks, smiles, you can easily sleep with the person without a condom. In such a situation I practice coitus interruptus since when he releases inside me, he can give me diseases."

Male sex worker, 32 years old

MSM were also less likely to use condoms in their marriages to women. Whereas 32 of 34 married MSM reported being sexually active with their wives, only 2 of 34 reported condom use at last sex.

\section{Lubrication use}

The vast majority of respondents (92 percent) reported using lubrication during anal sex. A wide variety of products were used (Figure 7); a great majority of respondents used oil-based products such as Vaseline or petroleum jelly ( 84 percent) and vegetable/food oils (10 percent). Oil-based products can undermine the effectiveness of latex condoms.

\section{Figure 7 Most commonly used lubricants*}

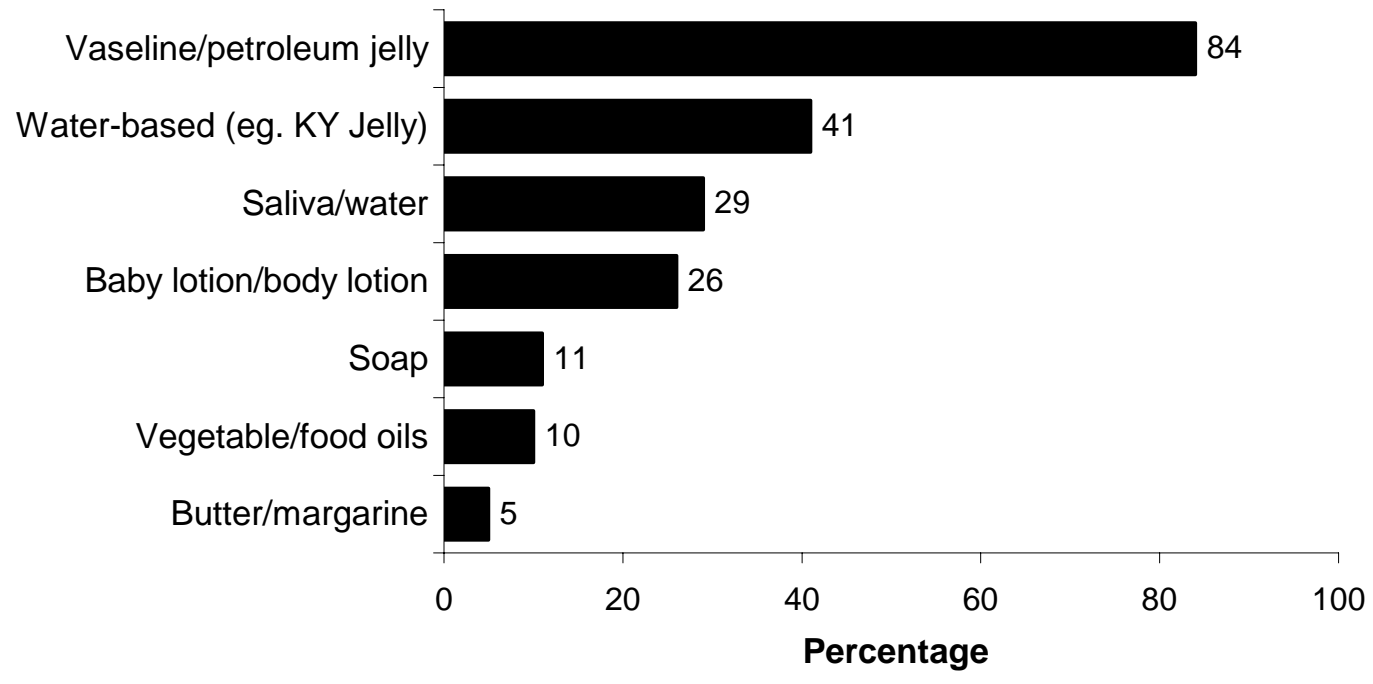

*Multiple responses allowed

Petroleum jellies are very cheap and readily available at most kiosks and market stands throughout Nairobi, which may contribute to their use. Unfortunately, a water-based lubricant like KY Jelly is not as accessible and affordable in Nairobi which may contribute to the fact that only 41 percent of respondents used it. Lack of knowledge about correct lubrication may also be an important factor; only 26 percent of respondents who know about lubrication $(n=475)$ correctly knew that only water-based products should be used with latex condoms. 


\section{Factors Associated With Unprotected Sex}

An aim of the study was to explore the factors associated with unprotected sex. Three types of reported noncondom use were examined as dependent variables: (a) at last receptive anal sex ( $\mathrm{n}=387)$, (b) at last insertive anal sex $(\mathrm{n}=427)$, and (c) noncondom use ever $(\mathrm{n}=500)$.

Respondents who reported never having either insertive or receptive anal sex with a man were excluded from the respective analysis.

Several key sociodemographic and other characteristics were then cross-tabulated with these outcomes to identify statistically significant associations with noncondom use. Characteristics were selected from the broad areas of sociodemographics, social relationships, discussion and support networks, stigma/discrimination/violence, HIV/STI information, sexual behavior, and exchange of money for sex. Table 15 shows the percentage of MSM with each characteristic who reported noncondom use, and indicates any significant relationship. 
Table 15 Percent reporting unprotected sex with men by key characteristics

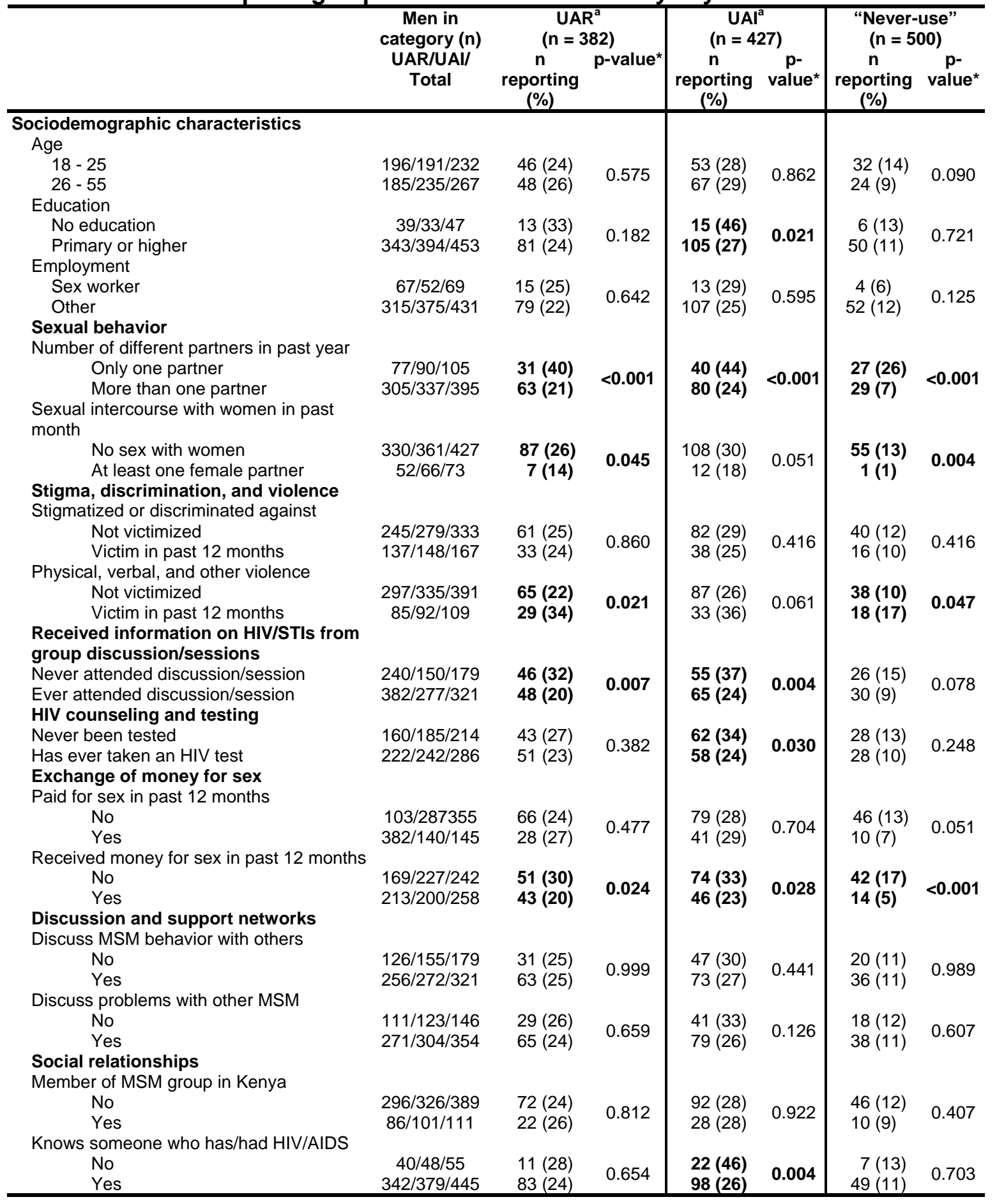

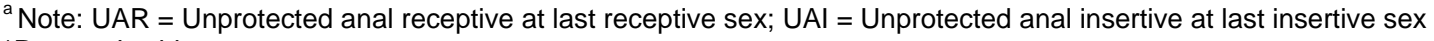
*Pearson's chi-square test 
The variables that were positively associated with any of the unprotected sex variables were: having no education, having only one partner in the past year, having no sex with a female partner in the past month, being a victim of physical/verbal/or other forms of violence, never having attended group discussions/sessions on HIV/STIs, never having been tested for HIV, not having received money in the last 12 months for sex, and not knowing someone with HIV/AIDS.

These variables were then added to multiple logistic regression models. Odds ratios were obtained, adjusting for all other factors, as shown in Table 16.

Table 16 Multivariate analysis of predictor variables related to unprotected sex with men

\begin{tabular}{|c|c|c|c|c|c|c|}
\hline & \multicolumn{2}{|c|}{$\begin{array}{c}\text { UAR }^{a} \\
n=282 \\
r^{2}=0.08\end{array}$} & \multicolumn{2}{|c|}{$\begin{array}{c}\mathrm{UAl}^{\mathrm{a}} \\
\mathrm{n}=427 \\
\mathrm{r}^{2}=0.09\end{array}$} & \multicolumn{2}{|c|}{$\begin{array}{c}\text { "Never-use" of } \\
\text { condoms } \\
n=500 \\
r^{2}=0.16\end{array}$} \\
\hline & $\begin{array}{l}\text { Odds } \\
\text { ratio }^{\text {b }}\end{array}$ & $95 \% \mathrm{Cl}$ & $\begin{array}{l}\text { Odds } \\
\text { ratio }^{\text {b }}\end{array}$ & $95 \% \mathrm{Cl}$ & $\begin{array}{l}\text { Odds } \\
\text { ratio }^{\text {b }}\end{array}$ & $95 \% \mathrm{Cl}$ \\
\hline Has primary or higher education & 0.63 & $(0.29-1.38)$ & 0.45 & $\left(0.20-1.00^{c}\right)^{*}$ & 0.67 & $(0.24-1.88)$ \\
\hline $\begin{array}{l}\text { Had only } 1 \text { male partner in past } 12 \\
\text { months }\end{array}$ & 2.44 & $(1.32-4.52)^{\star *}$ & 2.57 & $(1.48-4.46)^{\star \star}$ & 3.23 & $(1.68-6.19)^{\star \star \star}$ \\
\hline $\begin{array}{l}\text { Had } 1 \text { or more female sexual } \\
\text { partners in past month }\end{array}$ & 0.57 & $(0.24-1.35)$ & 0.70 & $(0.35-1.41)$ & 0.13 & $(0.02-0.96)^{*}$ \\
\hline $\begin{array}{l}\text { Victim of physical, verbal, or other } \\
\text { violence in past } 12 \text { months }\end{array}$ & 2.44 & $(1.35-4.39)^{* *}$ & 1.96 & $(1.13-3.37)^{*}$ & 2.45 & $(1.24-4.84)^{*}$ \\
\hline $\begin{array}{l}\text { Has ever attended discussion } \\
\text { group or session on HIVISTIs }\end{array}$ & 0.53 & $(0.31-0.89)^{\star}$ & 0.61 & $(0.37-0.99)^{\star}$ & 0.56 & $(0.30-1.07)$ \\
\hline Has ever had an HIV test & 0.87 & $(0.52-1.47)$ & 0.71 & $(0.44-1.13)$ & 0.70 & $(0.37-1.33)$ \\
\hline $\begin{array}{l}\text { Has received money for sex in } \\
\text { past } 12 \text { months }\end{array}$ & 0.52 & $(0.30-0.92)^{*}$ & 0.58 & $(0.35-0.95)^{*}$ & 0.26 & $(0.12-0.54)^{* * *}$ \\
\hline $\begin{array}{l}\text { Knows someone who has/had } \\
\text { HIVIAIDS }\end{array}$ & 0.85 & $(0.37-1.91)$ & 0.43 & $(0.22-0.85)^{*}$ & 1.05 & $(0.41-2.71)$ \\
\hline
\end{tabular}

${ }^{\mathrm{a}} \mathrm{UAR}=$ Unprotected anal receptive at last sex; UAI = Unprotected anal insertive at last sex

${ }^{\mathrm{b}}$ Odds ratios are based on multiple logistic regression adjusting for all other factors

${ }^{c}$ Upper confidence limit includes 1.00 due to rounding up.

${ }^{*} \mathrm{p}<0.05,{ }^{* *} \mathrm{p}<0.01,{ }^{* *} \mathrm{p}<0.001$

Having only one partner in the past twelve months was an important predictor of the three unprotected sex variables. For example, MSM with one partner over the last year were 2.44 times as likely to not use condoms during their last act of receptive anal intercourse compared to MSM with two or more partners.

Similarly, MSM who reported being victimized by various forms of violence were more likely to have unprotected sex. For example, MSM who had experienced physical, verbal or other forms of 


\section{Hgrizons}

violence in the past year were 2.45 times as likely to have never used condoms compared to those who did not report violence.

Some factors were found to have a protective effect. For example, MSM who had ever attended a discussion group or session on HIV or STIs were about half as likely to not have used condoms during the last act of insertive and receptive anal sex compared to those who never attended such groups or sessions.

MSM with some formal education (primary or higher) were about half as likely to not have used a condom during the last act of insertive anal sex compared to those with no formal education. Those MSM who know someone with HIV/AIDS were also half as likely to not have used a condom during the last act of insertive anal intercourse compared to those who do not know anyone who is infected.

Those having at least one female sexual partner in the last month were significantly less likely to "never" use condoms. MSM also seemed to be wary of possible higher-risk sexual contacts, as those who receive money for sex were much less likely to have any unprotected anal sex.

\section{Reported STI Symptoms and Treatment}

During the quantitative interviews, eight commonly reported STI symptoms were listed, and respondents were asked if they had ever had the symptom and, if so, where they had sought treatment or care. Even though condom use is reportedly high, 47 percent of respondents reported ever having an STI symptom. Over 25 percent of respondents reported ever having genital pain, genital or anal discharge, burning urination, and/or genital or anal itching (Table 17). The highest reported symptoms in the past 12 months were genital pain (12 percent), genital or anal discharge (6 percent), burning urination (14 percent), and genital or anal itching (11 percent). 
Table 17 Reported STI symptoms and treatment $(n=500)$

\begin{tabular}{lc}
\hline & $\%$ \\
\hline Genital pain & 36 \\
Ever had symptom & 28 \\
Was treated last time had symptom & 12 \\
Experienced symptom in past 12 months & \\
Genital/anal discharge & 25 \\
Ever had symptom & 23 \\
Was treated last time had symptom & 6 \\
Experienced symptom in past 12 months & \\
Burning urination & 35 \\
Ever had symptom & 29 \\
Was treated last time had symptom & 14 \\
Experienced symptom in past 12 months & \\
Genital/anal itching & 29 \\
Ever had symptom & 21 \\
Was treated last time had symptom & 11 \\
Experienced symptom in past 12 months & \\
Genital/anal sores & 15 \\
Ever had symptom & 14 \\
Was treated last time had symptom & 5 \\
Experienced symptom in past 12 months & 11 \\
Testicular pain & 10 \\
Ever had symptom & 4 \\
Was treated last time had symptom & 2 \\
Experienced symptom in past 12 months & \\
Swelling in the groin & \\
Ever had symptom & \\
Was treated last time had symptom & \\
Experienced symptom in past 12 months & \\
\hline
\end{tabular}

These rates were higher than for STI symptoms reported in the 2003 Kenya DHS. Of 327 men interviewed in Nairobi province, one percent reported having abnormal genital discharge and two percent reported having genital sores/ulcers in the past 12 months. The national rate for all males surveyed in Kenya $(n=2,825)$ was similar: two percent reported having abnormal genital discharge and two percent reported having genital sores/ulcers.

The treatment-seeking rate for MSM who reported any symptom in the past 12 months $(\mathrm{n}=233)$ was 80 percent. Respondents were most likely to seek treatment for genital or anal discharge (95 percent, $\mathrm{n}=122$ ) than any other symptom. This figure is close to the 2003 DHS data 


\section{Hgrizons}

in which 90 percent of men in Kenya who reported having abnormal genital discharge or genital sores/ulcers $(\mathrm{n}=88)$ reported obtaining advice or treatment for the symptom.

Respondents who reported ever having these symptoms identified where they sought treatment. Private clinics were the most popular treatment source, followed by hospitals, health posts, and health centers (Table 18). Self-medication and traditional healers were less utilized. Qualitative informants also reported a preference for private clinics, which are believed to be more sensitive to confidentiality.

Table 18 Where respondents sought treatment last time, by reported STI symptom*

\begin{tabular}{|c|c|c|c|c|c|c|c|}
\hline & $\begin{array}{c}\text { Genital } \\
\text { pain } \\
\% \\
n=137\end{array}$ & $\begin{array}{c}\text { Genital/ } \\
\text { anal } \\
\text { discharge } \\
\% \\
n=116\end{array}$ & 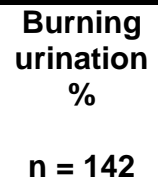 & $\begin{array}{c}\text { Genital/ } \\
\text { anal } \\
\text { itching } \\
\% \\
n=105\end{array}$ & $\begin{array}{c}\text { Genitall } \\
\text { anal } \\
\text { sores } \\
\% \\
n=66\end{array}$ & $\begin{array}{c}\text { Testicular } \\
\text { pain } \\
\% \\
n=41\end{array}$ & $\begin{array}{c}\text { Swelling } \\
\text { in the } \\
\text { groin } \\
\% \\
n=48\end{array}$ \\
\hline Private clinic & 42 & 38 & 46 & 43 & 36 & 29 & 44 \\
\hline Hospital & 25 & 28 & 24 & 24 & 27 & 39 & 27 \\
\hline Health post & 10 & 10 & 9 & 8 & 6 & 10 & 8 \\
\hline Health center & 12 & 12 & 10 & 8 & 11 & 12 & 10 \\
\hline Self-medicated & 6 & 6 & 6 & 12 & 9 & 7 & 6 \\
\hline Traditional healer & 4 & 3 & 3 & 4 & 8 & 2 & 4 \\
\hline Others & 1 & 2 & 3 & 2 & 3 & 0 & 0 \\
\hline
\end{tabular}

*Multiple responses allowed

\section{Factors Associated With STI Symptoms}

The high level of reported STI symptoms is of key concern to HIV programs that seek to deliver services to MSM in Nairobi. Further analysis was done to identify potential risk factors. The same list of MSM characteristics used for the previous unprotected sex analysis (Table 15) was crosstabulated with those respondents who reported at least one STI symptom in the past 12 months. Sexual behavior variables of "unprotected anal sex with men," "ever had group sex," and "practices include oral sex" were added to the variables used in Table 15; the results are shown in Table 19. 
Table 19 Percent reporting STI symptoms in last 12 months by MSM characteristics

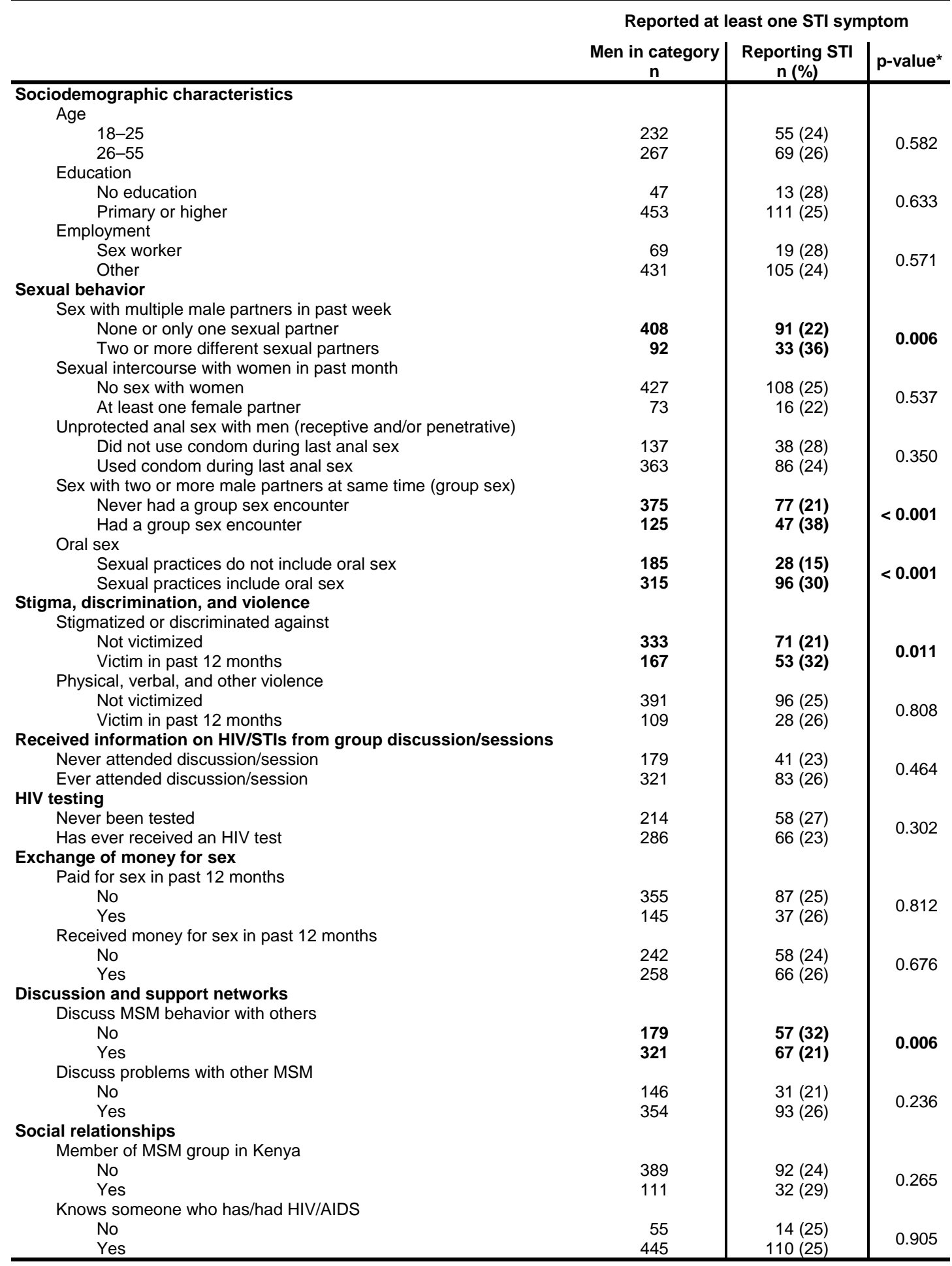

*Pearson's chi-square test 


\section{Hgrizons}

Factors significantly associated with reported STI symptoms included: sex with two or more partners in the past week, ever having a group sex encounter, and reporting oral sex as a sexual practice. Those who reported a stigmatizing or discriminatory incident within the past 12 months were also significantly more likely to report STI symptoms. Those who reported discussing their MSM sexual behavior with other people, however, were less likely to have an STI. Lack of condom use at last anal sex, however, was not found to be significantly associated with reported STI symptoms.

The five indicators associated with reported STI symptoms were further analyzed using logistic regression, and then multiple logistic regression was used to adjust for all factors in the model (Table 20). When controlling for all factors, reporting multiple partners was no longer significant at the $\mathrm{p}=0.05$ level, whereas having a group sex encounter was more closely associated with reported STIs $(\mathrm{p}=0.052)$. Being a victim of stigmatizing and discriminatory incidents remained a significant predicting factor. Discussion of MSM sexual behavior also retained a significant protective effect against reported STI symptoms.

Table 20 Multivariate analysis of predictor variables related to reported STI symptoms in the past 12 months

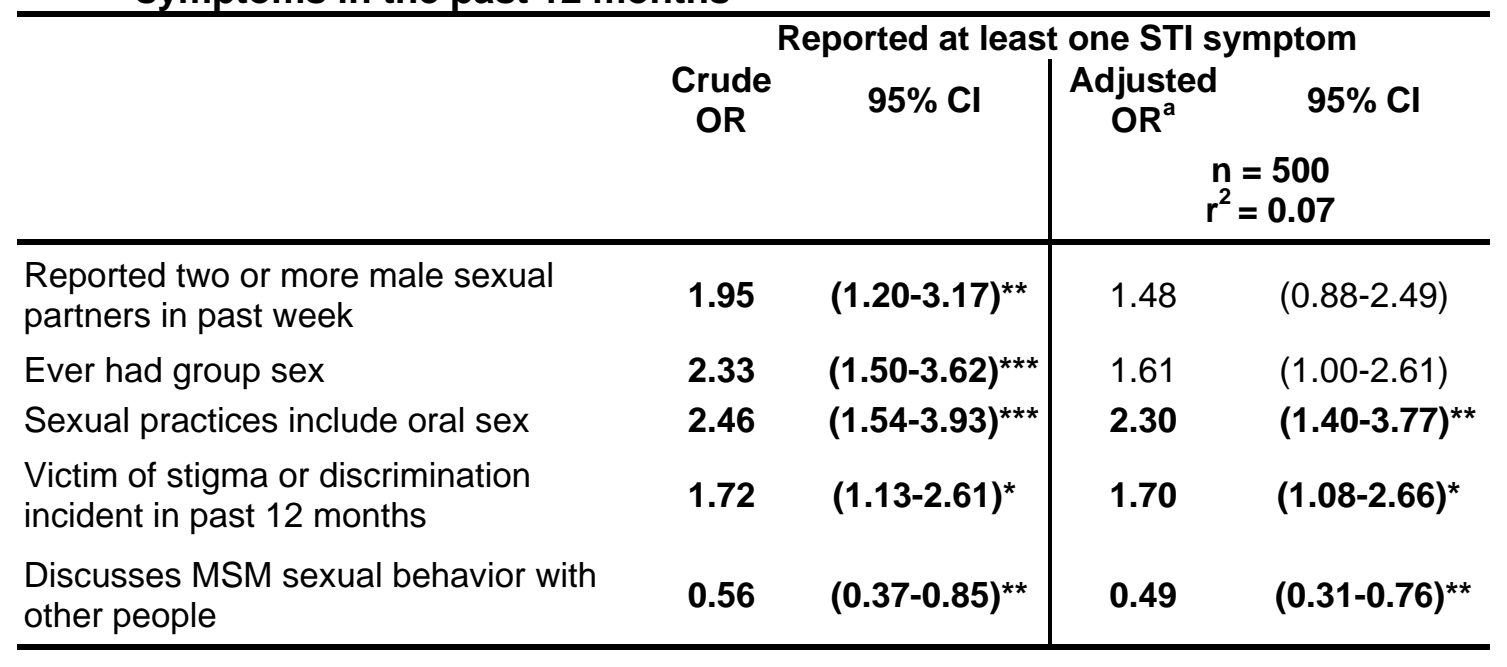

${ }^{\text {a }}$ Adjusted odds ratios are based on multiple logistic regression adjusting for all other factors ${ }^{*} p<0.05,{ }^{* *} p<0.01,{ }^{* *} p<0.001$

Oral sex practice remained associated with reported STI symptoms. Qualitative interviews with selected service providers revealed that some MSM patients have exhibited "non-routine" clinical STI symptoms such as anal sores, as well as sores or ulcers in the throat. One provider expressed his concerns when he said, "at first I couldn't understand how a man can contract anal sores after sex with a woman."

The questionnaire did not elicit whether oral sex was given and/or received by respondents during specific or typical sexual encounters. It was also not possible to determine whether an STI episode reported in the "genital and/or anal region" was specifically genital or anal in nature. Despite these 
weaknesses in the study design, it was possible to determine whether oral sex practice overall was associated with each of the reported STIs. Table 21 shows the difference in reported STI symptoms between MSM who reportedly practice oral sex and MSM who do not.

Table 21 Percent reporting STI symptom in past 12 months by oral sex practice

\begin{tabular}{lccc}
\hline & $\begin{array}{c}\text { Sexual practices include oral sex? } \\
\text { No }\end{array}$ & $\begin{array}{c}\text { Yes } \\
\mathbf{n = 1 8 5}\end{array}$ & $\begin{array}{c}\text { p-value } \\
\mathbf{n}=\mathbf{3 1 5}\end{array}$ \\
& $\mathbf{\%}$ & $\mathbf{\%}$ & \\
\hline Genital pain & 8 & 9 & 0.025 \\
Genital/anal discharge & 1 & 19 & $<0.001$ \\
Burning urination & 5 & 11 & $<0.001$ \\
Genital/anal itching & 9 & 8 & 0.432 \\
Genital/anal sores & 0 & 4 & $<0.001$ \\
Testicular pain & 1 & 4 & $0.064^{\star *}$ \\
Swelling in the groin & 4 & & 0.866 \\
\hline
\end{tabular}

*Pearson's chi-square test

**Fisher's exact test

Most symptoms were highly associated with oral sex, with the exception of genital/anal itching, testicular pain, and swelling in the groin. Oral sex practitioners were significantly more likely than others to experience genital pain, burning urination, genital/anal discharge, and genital/anal sores. Genital/anal discharge and genital/anal sores were reported nearly exclusively by MSM who practice oral sex. Whereas these data may show that oral sex could be a complex indicator of risky sexual behavior, the possibility must be considered that unprotected oral sex may be a potential transmission route for certain STIs among MSM (Edwards and Carne 1998).

\section{HIV Testing}

Voluntary counseling and testing for HIV is widely available, with over 70 VCT sites registered in Nairobi Province with the National AIDS Control Program (NASCOP).

DHS data indicate that 86 percent of males in Nairobi $(n=376)$ have heard of VCT $(\mathrm{CBS}, \mathrm{MOH}$, and ORC Macro 2004). As with the general population, MSM in the study are highly aware of the availability of VCT. Of those respondents who had not been tested for HIV, 95 percent knew where to go for VCT. The curriculum for VCT counselors, however, does not take into consideration the possibility that male clients may be having sex with other men. As a result, VCT centers in Nairobi are not prepared to provide specialized prevention advice to MSM, nor to address the particular aspects and ramifications of partner notification and couples' testing for this population.

Despite the barriers to receiving specialized HIV counseling and testing, 57 percent of MSM respondents reported ever having taken an HIV test. This is more than double the rate of the 


\section{Hgrizons}

general population of Nairobi males; according to 2003 DHS data, 27 percent of 376 men in Nairobi reported ever taking an HIV test. Of the 286 MSM respondents who have received an HIV test, nearly all ( 98 percent) received their results after testing, and 70 percent were tested within the past 12 months.

Most of the MSM who were tested did not provide a specific reason for seeking the test, citing a voluntary decision to test or simply wanting to know their status (Table 22). MSM obtained VCT from a wide variety of hospitals, health centers, and VCT centers, with Kenyatta National Hospital the most widely used, followed by Nairobi Hospital, Casino VCT Center, and Liverpool VCT Center.

Table 22 HIV testing $(n=286)$

\begin{tabular}{lr}
\hline & $\%$ \\
\hline Reasons for seeking HIV test & 69 \\
Voluntary decision/to know status & 11 \\
During a check-up/suggested by medical staff & 7 \\
Requirement of employment/school admission/marriage/travel & 4 \\
Discussed with partner & 9 \\
Others & \\
Where test was received & 23 \\
Kenyatta National Hospital & 7 \\
Nairobi Hospital & 7 \\
VCT Casino & 5 \\
VCT Liverpool & 14 \\
Other hospital (over five others mentioned) & 14 \\
Other clinic/health center (over 10 others mentioned) & 27 \\
Other VCT center (over 15 others mentioned) & 4 \\
Others & \\
\hline
\end{tabular}

The popularity of Kenyatta National Hospital as a VCT site may be because of lower costs as well as the ability of MSM to remain "anonymous" and blend in among the many people who seek general and VCT services at the hospital. Kenyatta National Hospital VCT Centre has been in operation longer than other sites mentioned, and its staff may be more friendly and responsive to the needs of the diverse clients who seek their services. Nairobi Hospital is a private facility, with a reputation for providing high-quality care and services at a high cost.

VCT Casino is located in the city center, and is favored by some MSM respondents because of its central location and the availability of STI treatment as well as HIV testing services. At the time of the survey, VCT Liverpool — located just outside the central business district — was beginning to provide a "male-friendly" clinic twice-weekly, and was starting to attract MSM clients. 
The reasons given for not seeking an HIV test by those MSM who reported not being tested $(\mathrm{n}=212)$ were "feeling healthy" (51 percent), "afraid of learning status" (42 percent), "knowing/trusting themselves" ( 8 percent), or not having the money for a test ( 5 percent). Lack of knowledge of VCT services was not a barrier to testing, as 95 percent of untested MSM were aware of a site that offered VCT.

Despite use of VCT services by many MSM respondents, in-depth interviews with VCT providers revealed that most do not acknowledge signs that some clients may be MSM, and operationally assume that all clients are heterosexual. During counseling, these providers made no mention of which lubricants are appropriate for use with condoms, which is essential for preventing HIV and certain STIs via anal sex. The situation was different, however, at the only VCT center in Nairobi that includes a "male-friendly" clinic: VCT Liverpool. Here, some services are tailored to meet the needs of both MSM and heterosexuals.

\section{Access to Health Care and Provider Preferences}

As discussed previously, the MSM in this study access a wide range of available health facilities for both STI treatment (Table 18) and VCT (Table 22). These facilities include hospitals, health centers, and clinics, both private and public, reflecting the diversity of the numerous health care facilities in Nairobi. Although the wide availability of health care options is an advantage, MSM respondents still claim they have trouble finding confidential, affordable, and quality care that meets their unique HIV/STI prevention needs.

When asked why they chose a health facility for STI treatment, MSM respondents cited confidentiality as their chief concern, followed by affordability (Table 23). Other factors included referrals by friends/acquaintances, desire for quality and/or specialized treatment, familiarity with the caregiver, and proximity or location of the service provider.

Table 23 Why respondents selected treatment facility, by reported STI

\begin{tabular}{|c|c|c|c|c|c|c|c|}
\hline & $\begin{array}{c}\text { Genital } \\
\text { pain } \\
\% \\
n=137\end{array}$ & $\begin{array}{c}\text { Genital/ } \\
\text { anal } \\
\text { discharge } \\
\% \\
n=116\end{array}$ & $\begin{array}{c}\text { Burning } \\
\text { urination } \\
\% \\
n=141\end{array}$ & $\begin{array}{c}\text { Genital/ } \\
\text { anal } \\
\text { itching } \\
\% \\
n=105\end{array}$ & $\begin{array}{c}\text { Genital/ } \\
\text { anal } \\
\text { sores } \\
\% \\
\mathrm{n}=66\end{array}$ & $\begin{array}{c}\text { Testicular } \\
\text { pain } \\
\% \\
n=41\end{array}$ & $\begin{array}{c}\text { Swelling } \\
\text { in the } \\
\text { groin } \\
\% \\
n=48\end{array}$ \\
\hline Confidentiality & 37 & 32 & 36 & 36 & 32 & 22 & 31 \\
\hline Affordability & 18 & 17 & 19 & 14 & 18 & 22 & 25 \\
\hline $\begin{array}{l}\text { Referred by } \\
\text { friend/acquaintance }\end{array}$ & 12 & 13 & 13 & 11 & 12 & 5 & 10 \\
\hline $\begin{array}{l}\text { Quality/specialized } \\
\text { treatment at facility }\end{array}$ & 15 & 11 & 9 & 9 & 14 & 12 & 10 \\
\hline $\begin{array}{l}\text { Knows the } \\
\text { caregivers }\end{array}$ & 10 & 10 & 9 & 10 & 8 & 12 & 4 \\
\hline Proximity/location & 2 & 14 & 12 & 13 & 15 & 24 & 17 \\
\hline Others & 6 & 4 & 2 & 8 & 2 & 2 & 2 \\
\hline
\end{tabular}




\section{Hgrizons}

Although many of these reasons are general concerns anyone might consider in selecting a health care provider, study data highlight that MSM are primarily concerned about exposure of their sexual identity, as well as how the health care staff might react if informed about their sexual behavior.

MSM respondents were also asked from whom they would seek advice or treatment if any STI symptoms were to appear. Several different preferred advisors and/or providers were mentioned (Table 24). For the most part, professional health care providers - public or private - were the preferred choice. However, 41 percent of respondents said they would prefer to seek advice, a referral, or treatment from a fellow MSM, probably because of concerns about confidentiality. These findings suggest that professional and confidential care and advice is strongly desired.

\section{Table 24 From whom MSM would seek advice or treatment regarding STI} symptoms $(n=286)^{*}$

\begin{tabular}{lc}
\hline Preferred advisor/provider & $\%$ \\
\hline Health worker (private) & 43 \\
Health worker (public) & 42 \\
Fellow MSM & 41 \\
Doctor: male and/or gay and/or specialized & 29 \\
Sexual partner & 8 \\
Others (CBO/NGO counselors, peer educators, VCT centers, & $<5$ each \\
outreach workers, relatives, chemist, traditional/herbal, others) & \\
\hline
\end{tabular}

*Multiple responses possible

In-depth interviews with service providers revealed that the issue of MSM sexual behavior is rarely discussed among providers, even though they are aware of patients who present with symptoms that may indicate that they have sex with other men. Such symptoms include sores or ulcers in the throat or anal region, but these symptoms are usually treated without questioning or inquiry. This has resulted in an unofficial "don't ask, don't tell" policy because of the stigma associated with same-sex relationships, as well as the fear of legal implications.

"Most of the MSM clients are shy when seeking services; they don't say exactly what they are suffering from. Later, they say 'I have a problem but I don't know how I will put it or describe it.' They take a lot of time; examining them is not easy."

Nurse, STI clinic

Just as it is rare for providers to inquire about MSM sexual behavior, it is rare for MSM to reveal their sexual behavior to health providers.

"It is difficult to provide services to MSM clients when they don't disclose the problem. I met one suffering from anal sores, but he said he was having anal allergy. It was difficult to know what to treat."

Clinical officer, STI clinic 
Another nurse expressed this culture of silence among providers:

"I have not come across a man who says he is an MSM, but I have encountered situations where patients come with discharge. After screening, we don't go further to ask if he has anal discharge. The medication we give to the patients can cure both (penile and anal) discharge."

Nurse, private clinic

To improve utilization and provide appropriate care, HIV/STI services in Nairobi will need to be adapted and staff trained to better respond to the health and confidentiality concerns of MSM. 


\section{Conclusion and Recommendations}

The results from this research provide important information on the background characteristics, sexual behavior, and health-seeking practices of a sample of MSM in Nairobi, Kenya. Despite the limitations of the snowball sampling methodology, researchers were able to reach a diverse group of MSM and elicit qualitative and quantitative data that can be used to inform HIV/STI programming in Kenya. The study also shows that research on MSM can be done in Kenya despite such obstacles as widespread stigmatization of MSM behavior and the fact that it is illegal.

Overall, the survey data indicate that a majority of MSM respondents are aware of HIV/STI risks and are taking steps to protect their health. These steps include getting tested for HIV, seeking professional treatment for STI symptoms, and using condoms. However, condom use is not universal, particularly among those who are in long-term sexual relationships with only one partner, and/or are victims of physical, verbal, and/or sexual violence. Moreover, the prevalence of reported STI symptoms is higher in the study sample than in men in the general population (CBS, $\mathrm{MOH}$, and ORC Macro 2004), which may facilitate the acquisition and transmission of HIV.

The ease with which this study recruited 500 men through snowball sampling suggests that the population of Kenyan MSM living in Nairobi is larger than is commonly believed. This situation, combined with the existence of risk behaviors, such as unprotected sex, among the study sample may have implications for the development of localized STI and HIV epidemics. Therefore, interventions targeted to this population are urgently needed. These interventions could include the following:

\section{Specialized counseling as part of VCT and STI services that is confidential and sensitive to the HIV/STI prevention needs of MSM.}

Although a high percentage of MSM in the survey sample have taken an HIV test, VCT services have not trained counselors to provide care and advice to meet the specific sexual health needs of MSM. The situation is similar in many STI clinics, where providers rarely discuss treatment and prevention issues relevant to their MSM clients. Stigmatizing attitudes of providers and their lack of sensitivity are significant barriers to receiving appropriate health services. MSM desire confidential, affordable, and quality care, and prefer to receive this care from professional health care providers. To improve utilization, services will need to respond to MSM concerns about stigmatization of their sexual behavior and their desire for strict confidentiality. Thus, VCT and STI clinic staff need training on the HIV/STI prevention needs of MSM, counseling strategies for addressing risk behaviors, and the importance of confidential and de-stigmatizing service delivery.

\section{Peer education that addresses the HIV/STI risks of multiple partners, unprotected sex, and incorrect use of lubrication.}

The study found that other MSM - whether as partners or friends - play an important role in passing on information about HIV and other STIs. These discussions revolve around preventive 
and protective measures that can be adopted by MSM and that respond to their needs. Study findings also highlight the importance of increasing exposure to discussions about HIV/STIs between MSM because respondents who had attended a discussion group or session were significantly more likely to use condoms. In addition, a high proportion of survey respondents noted that they would seek advice regarding STI symptoms from other MSM, which also supports the notion of training MSM as HIV/STI peer educators.

These peer educators could be trained to encourage the use of water-based lubricants for anal sex, the use of condoms for any penetrative sex act with male or female partners, and a reduction in the number of sexual partners. Peer educators could also help MSM explore the issues of partner trust and intimacy as barriers to condom use, particularly among those in longer-term relationships with a single partner. These issues are not unique to MSM, but are also formidable obstacles to condom use within heterosexual relationships.

Peer education may also have an important role to play in helping MSM who are more marginalized within society - those who have been victims of stigma, discrimination, or violence. The study found that these MSM were more likely to engage in unprotected sex and report STI symptoms. A peer education program that emphasizes personal empowerment and responsibility, and offers social support may help this particularly vulnerable population to adopt HIV/STI protective behaviors. 


\section{Hgrizons}

\section{References}

Attipoe, Dela. 2004. "Fighting HIV in Ghana requires addressing homosexuality" Essay based on the study

"Revealing the Pandora Box or Playing the Ostrich?: A Situational Appraisal of Men Having Sex with Men in the Accra, Ghana Metropolitan Area and its Environs.” The Gully 2004-2005: Online magazine. http://www.thegully.com/essays/gaymundo/0403_gay-men_hiv_ghana/msm_ghana_intro_summary.html, accessed August 16, 2005.

Caldwell, B. et al. 2000. "Sexual regimes and sexual networking: The risk of an HIV epidemic in Bangladesh," in J.C. Caldwell et al. (eds.) Towards the Containment of the AIDS Epidemic: Social and Behavioral Research. Canberra, Australia: Health Transition Centre of the Australian National University, pp 21-38.

Central Bureau of Statistics (CBS) [Kenya], Ministry of Health (MOH) [Kenya], and ORC Macro. 2004. Kenya Demographic and Health Survey 2003. Calverton, Maryland: CBS MOH, and ORC Macro.

“Clerics say no to gay marriages,” East African Standard, July 2, 2003.

Edwards, S. and C. Carne. 1998. "Oral sex and transmission of non-viral STIs," Sexually Trasmitted Infections 74: 95-100.

Ellen, R.F. (ed). 1984. Ethnographic Research: A guide to general conduct. London: Academic Press Limited.

“Encounters with gays at a city pub,” East African Standard, Aug 18, 2003.

Hanson, J. et al. 2005. “Assessment of sexually transmitted diseases as risk factors for HIV seroconversion in a New Orleans sexually transmitted disease clinic, 1990-1998,” Annals of Epidemiology 15(1): 13-20.

Horizons Program. 2002. "Meeting the sexual health needs of men who have sex with men in Senegal," Horizons Final Report. Washington, D.C.: Population Council.

Kalichman, S.C. 2000. "HIV transmission risk behaviors of men and women living with HIV/AIDS: Prevalence, predictors, and emerging clinical interventions," Clinical Psychology: Science and Practice 7: 32-47.

Kerr-Pontes, Ligia RS et al. 1999. "Self-reported sexual behavior and HIV risk taking among men who have sex with men in Fortaleza, Brazil," AIDS 13(6): 709-717.

Kiama, W. 1999. “Where are Kenya’s homosexuals?” AIDS Analysis Africa 9(5): 9-10.

Mackay, Tim. 2001. "Sexual health of males in South Asia who have sex with other males: Results of situational assessments in four cities in India and Bangladesh." London: Resource Centre for Sexual and Reproductive Health (JSI UK).

Marks, G., S. Burris, and T.A. Peterman. 1999. "Reducing sexual transmission of HIV from those who know they are infected: The need for personal and collective responsibility,” AIDS 13(3): 297-306.

McKenna, N. 1996. On the Margins: Men Who Have Sex with Men and HIV in the Developing World. London: PANOS Institute.

Mills, S. et al. 2004. "Surveillance and modeling of HIV, STI, and risk behaviors in concentrated HIV epidemics," Sexually Transmitted Infections 80(Suppl 11): ii57-ii62. 
McKeganey, N.P. 1994. "Prostitution and HIV: What do we know and where might research be targeted in the future?," AIDS 8(9): 1215-1226.

Murray, S.O. 1998. "Homosexuality in 'traditional' sub-Saharan Africa and contemporary South Africa.” An overview, in S. O. Murray and W. Roscoe (eds.). Boy-wives and Female Husbands. Studies on African Homosexualities. New York: St. Martin's Press, pp 1-18.

National Institutes of Health (NIH). 2002. Human Participant Protections Education for Research Teams. US Department of Health and Human Services.

Niang et al. 2003. “'It's raining stones': stigma, violence and HIV vulnerability among men who have sex with men in Dakar, Senegal," Culture, Health and Sexuality 5(6): 499-512.

Office of the United States Global AIDS Coordinator. 2004. "The President's emergency plan for AIDS relief: U.S five-year global HIV/AIDS strategy.” Washington DC: Office of the United States Global AIDS Coordinator.

Page-Shafer, K. et al. 2002. "Risk of HIV infection attributable to oral sex among men who have sex with men and in population of men who have sex with men," AIDS 16(17): 2350-2352.

Parker, R.G. and M. Carballo. 1990. "Qualitative research on homosexual and bisexual behavior relevant to HIV/AIDS,” The Journal of Sex Research 27(4): 497-525.

Parker, R.G., G. Herdt, and M. Carballo. 1991. "Sexual culture, HIV transmission and AIDS research," The Journal of Sex Research 28(1): 77-98.

Parsons, J.T. et al. 2003. "Correlates of sexual risk behaviours among HIV-positive men who have sex with men," AIDS Education and Prevention 15(5): 383-400.

Rajani, R. and M. Kudrati. 1996. "Varieties of sexual experience of the street children of Mwanza, Tanzania," in Sondra Zeidenstein and Kirsten Moore (eds.), Learning About Sexuality: A Practical Beginning. New York: Population Council and International Women's Coalition.

Robinson, E.K. and B.G. Evans. 1999. "Oral sex and HIV transmission,” AIDS 13(6): 737.

Rothenberg, R.B. et al. 1998. "Oral transmission of HIV,” AIDS 12(16): 2095-2105.

"Same-sex romance: Behind the veil of homosexuality.” East African Standard, September 5, 2004.

Sharma, A. et al. 2004. "HIV risk and prevention among men who have sex with men in Nairobi, Kenya," Poster presented at XV International AIDS Conference, Bangkok, Thailand.

Simooya, O.O. 2001. "Behind walls': a study of HIV risk behaviours and seroprevalence in prisons in Zambia," AIDS 15(13): 1741-1744.

Teunis, N. 2001. "Same-sex sexuality in Africa: A case study of Senegal," AIDS and Behavior 5(2): $173-182$.

UNAIDS. 2000. Report on Global HIV/AIDS epidemic. Geneva: UNAIDS.

2005. Web Site http://www.unaids.org/en/resources/faq/faq transmission.asp, accessed August 16, 2005.

UNAIDS and PANOS. 2001. Young Men and HIV: Culture, Poverty and Sexual Risk. Geneva: UNAIDS and PANOS 


\section{Hgrizons}

Varga, C.A. 2000. "Condom dilemmas: Dynamics of protected sex in high risk groups in South Africa," in J.C. Caldwell et al. (eds.) Towards the Containment of the AIDS Epidemic: Social and Behavioural Research. Canberra, Australia: Health Transition Centre of the Australian National University, pp 39-62.

2001. "The forgotten fifty percent: A review of sexual and reproductive health research and programs focused on boys and young men in Sub-Saharan Africa," African Journal of Reproductive Health 5(3): $175-195$. 


\section{Hgrizons}

Horizons is a global operations research program designed to:

- Identify and test strategies to improve HIV/AIDS prevention, treatment, and care programs and services.

- Disseminate best practices and promote research utilization with a view toward scaling up successful interventions.

\section{(2) Population Council}

Horizons is implemented by the Population Council in collaboration with

- International Center for Research on Women (ICRW)

- International HIV/AIDS Alliance

- Program for Appropriate Technology in Health (PATH)

- Tulane University

- Family Health International (FHI)

- Johns Hopkins University

For more information, please contact:

Horizons Program, Communications Unit 4301 Connecticut Avenue, NW Suite 280

Washington, DC 20008 USA

Tel: 202-237-9400

Fax: 202-237-8410

Email:horizons@pcdc.org

www.popcouncil.org/horizons 